Final Technical Report

High-Energy-Density Coating of High-Temperature Advanced Materials for Energy-Efficient Performance

June 2006

Principal Investigators:

Narendra B. Dahotre

University of Tennessee Space Institute

G. (Murali) Muralidharan

Vinod K. Sikka

Craig A. Blue

Oak Ridge National Laboratory

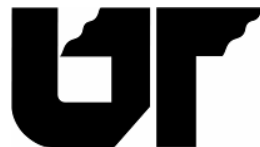

Space Institute

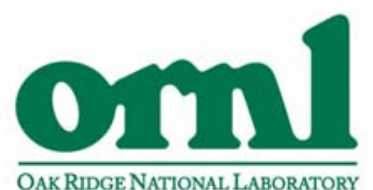

Managed by UT-Battelle, LLC 


\section{DOCUMENT AVAILABILITY}

Reports produced after January 1, 1996, are generally available free via the U.S. Department of Energy (DOE) Information Bridge.

Web site http://www.osti.gov/bridge

Reports produced before January 1, 1996, may be purchased by members of the public from the following source.

National Technical Information Service

5285 Port Royal Road

Springfield, VA 22161

Telephone 703-605-6000 (1-800-553-6847)

TDD 703-487-4639

Fax 703-605-6900

E-mailinfo@ntis.fedworld.gov

Web site http://www.ntis.gov/support/ordernowabout.htm

Reports are available to DOE employees, DOE contractors, Energy Technology Data Exchange (ETDE) representatives, and International Nuclear Information System (INIS) representatives from the following source.

Office of Scientific and Technical Information

P.O. Box 62

Oak Ridge, TN 37831

Telephone 865-576-8401

Fax 865-576-5728

E-mail reports@osti.gov

Web site http://www.osti.gov/contact.html 


\section{FINAL TECHNICAL REPORT}

Project Title:

High-Energy-Density Coating of High-Temperature Advanced Materials for Energy-Efficient Performance

Award No.:

DE-FC07-01ID14248

Project Period: $\quad$ September 30, 2001-December 31, 2004

PI: $\quad$ Narendra B. Dahotre (University of Tennessee)

(865) 974-3609

ndahotre@utk.edu

Additional Researchers: Dr. G. (Murali) Muralidharan (ORNL)

Dr. Vinod K. Sikka (ORNL)

Dr. Craig A. Blue (ORNL)

Recipient Organization: University of Tennessee-Knoxville

Industry Contact: $\quad$ Roman I. Pankiw

(724) 887-5100, Ext. 188

Duraloy Technologies, Inc.

120 Bridge Street

Scottdale, PA 15683-0081 



\title{
High-Energy-Density Coating of High-Temperature Advanced Materials for Energy-Efficient Performance
}

\author{
Narendra B. Dahotre \\ University of Tennessee Space Institute \\ Tullahoma, Tennessee \\ G. (Murali) Muralidharan, Vinod K. Sikka, and Craig A. Blue \\ Oak Ridge National Laboratory
}

June 2006

\author{
Prepared by \\ OAK RIDGE NATIONAL LABORATORY \\ P.O. Box 2008 \\ Oak Ridge, Tennessee 37831-6283 \\ managed by \\ UT-Battelle, LLC \\ for the \\ U.S. DEPARTMENT OF ENERGY \\ under contract DE-AC05-00OR22725
}




\section{Acknowledgments and Disclaimer}

\section{Acknowledgments}

This report is based upon work supported by the U.S. Department of Energy, Energy Efficiency and Renewable Energy, Industrial Technologies Program, Industrial Materials for the Future, under Award No. DE-FC07-01ID14248.

Research was sponsored by the U.S. Department of Energy, Office of Energy Efficiency and Renewable Energy, Industrial Technologies Program, under contract DE-AC05-00OR22725 with UT-Battelle, LLC.

The authors acknowledge the help in conducting various project tasks from Dr. S. Nayak, Dr. Raghuvir Singh, Mr. Anshul Singh, and Mr. Khangar of the University of Tennessee-Knoxville. The authors also wish to thank Dr. Peter Angelini, Oak Ridge National Laboratory, for program management and document review, and Carolyn Moser (ORNL) for technical editing.

\section{Disclaimer}

This report was prepared as an account of work sponsored by an agency of the United States Government. Neither the United States Government nor any agency thereof, nor any of their employees, makes any warranty, express or implied, or assumes any legal liability or responsibility for the accuracy, completeness, or usefulness of any information, apparatus, product, or process disclosed, or represents that its use would not infringe privately owned rights. Reference herein to any specific commercial product, process, or service by trade name, trademark, manufacturer, or otherwise, does not necessarily constitute or imply its endorsement, recommendation, or favoring by the United States Government or any agency thereof. The views and opinions of authors expressed herein do not necessarily state or reflect those of the United States Government or any agency thereof. 


\section{Contents}

List of Figures .

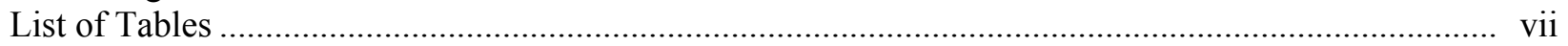

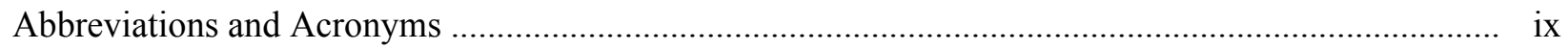

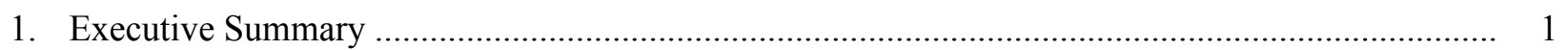

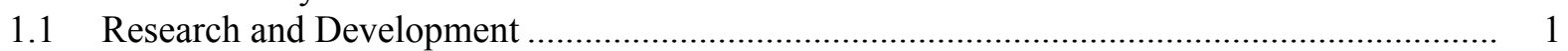

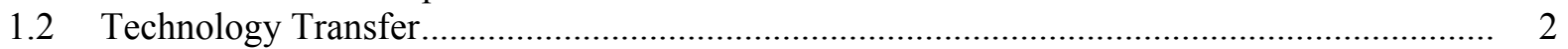

1.3 Commercialization............................................................................ 2

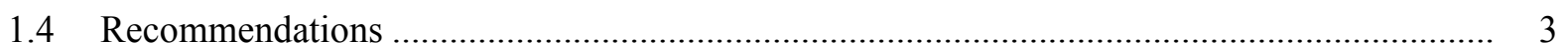

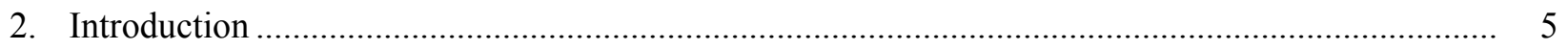

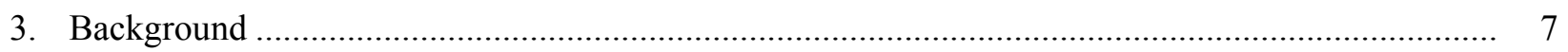

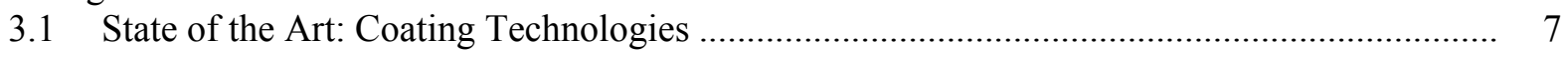

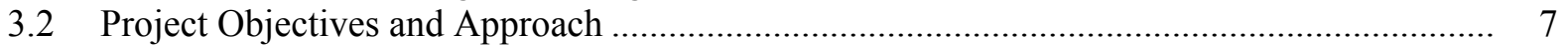

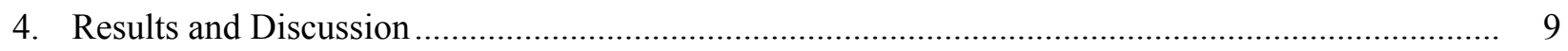

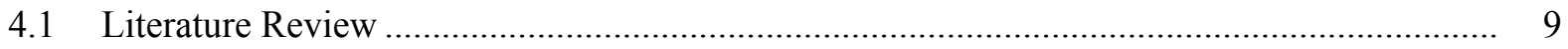

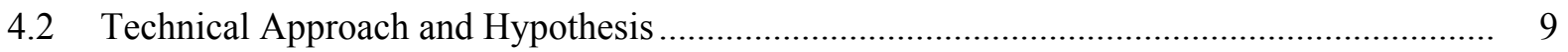

4.3 Experimental Methodology, Test Procedures, and Characterization Methods........................ 10

4.3.1 High-Energy-Density Processing: Infrared Plasma Arc Lamp and Laser .................. 10

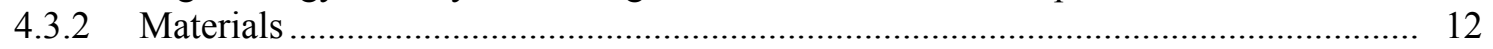

4.3.3 Test Procedures and Characterization Methods ................................................... 12

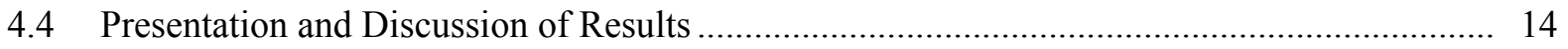

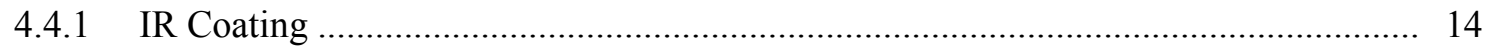

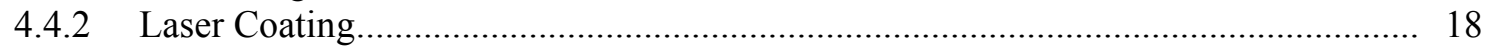

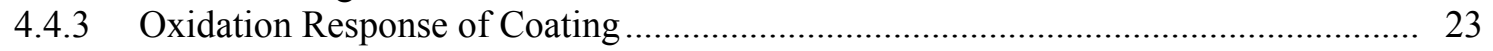

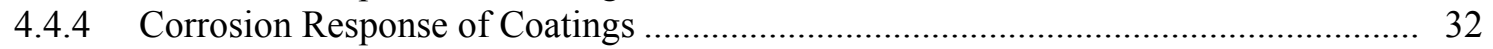

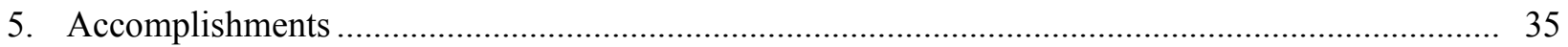

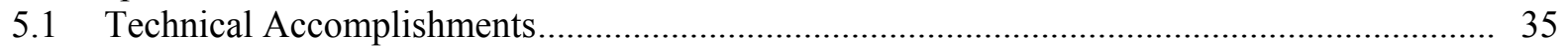

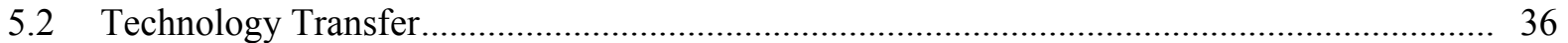

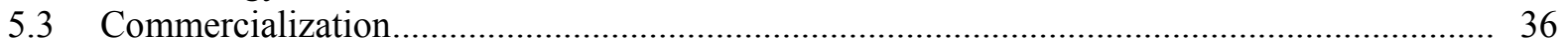

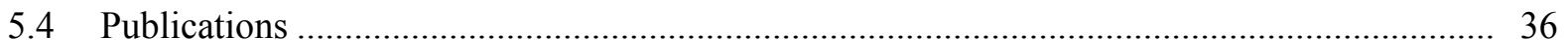

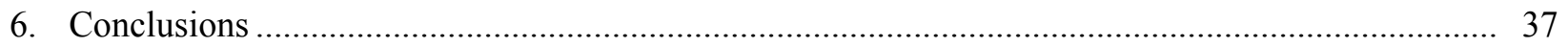

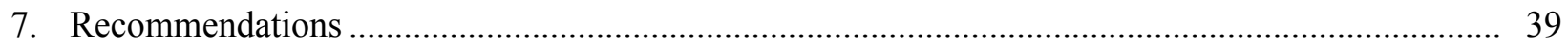

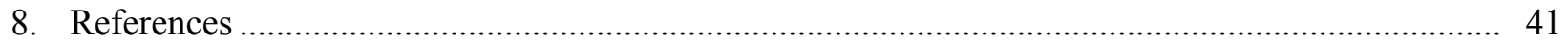





\section{List of Figures}

4.1 Control room and 3.5-kW plasma arc lamp at ORNL's Infrared Processing Center .............. 11

4.2 A cross-sectional optical micrograph of a 4340 steel substrate with Fe-Al alloy coating processed with a plasma arc lamp (processing condition 1).

4.3 X-ray diffraction pattern from sample processed with a plasma arc lamp (processing condition 1).....

4.4 A cross-sectional optical micrograph of a 4340 steel substrate with Fe-Al alloy coating processed with a plasma arc lamp (processing condition 2).

4.5 X-ray diffraction pattern from sample processed with a plasma arc lamp (processing condition 2).

4.6 Variations in Knoop hardness values as a function of distance perpendicular to the surface and of the process parameters in coatings processed using the plasma arc lamp........ 17

4.7 Composite coatings produced using a laser technique: (a) TiC/Al composite coating on 6061 aluminum alloy; (b) $\mathrm{TiB}_{2} /$ steel composite coating on 4340 steel.

4.8 High-resolution TEM images showing a nanosized reaction zone between the $\mathrm{TiB}_{2}$ particle and iron.

4.9 TEM image showing a reaction zone between the $\mathrm{TiB}_{2}$ particle and the corresponding EDS spectra

4.10 Cross-sectional optical micrographs of samples with Fe-Al alloy coatings prepared using $75 \mathrm{~mol} \% \mathrm{Al}$ precursor coating and a laser power of (a) $1250 \mathrm{~W}$, (b) $1500 \mathrm{~W}$, and (c) $1750 \mathrm{~W}$

4.11 Variation in iron and aluminum concentrations within the near-surface region as a function of laser power, obtained using EPMA

4.12 Variations in Knoop hardness values with laser power as a function of distance perpendicular to the surface in coatings prepared with (a) precursor layer with $43.5 \mathrm{~mol}$ $\% \mathrm{Al}$, and (b) precursor layer with $75 \mathrm{~mol} \% \mathrm{Al}$....

4.13 Variation in (a) normalized cumulative weight loss and (b) average Knoop hardness value over a $275-\mu \mathrm{m}$-thick region at the surface as a function of precursor aluminum content and laser power

4.14 Relationship between percentage of weight change and time of exposure for oxidized samples

4.15 X-ray diffraction (XRD) patterns obtained from Fe-Al alloy coatings prepared using $75 \mathrm{~mol} \% \mathrm{Al}$ precursor and a laser power of $1250 \mathrm{~W}$.

4.16 XRD patterns obtained from Fe-Al alloy coatings prepared using $75 \mathrm{~mol} \% \mathrm{Al}$ precursor and a laser power of $1500 \mathrm{~W}$

4.17 XRD patterns obtained from $\mathrm{Fe}-\mathrm{Al}$ alloy coatings prepared using $75 \mathrm{~mol} \% \mathrm{Al}$ precursor and a laser power of $1750 \mathrm{~W}$.

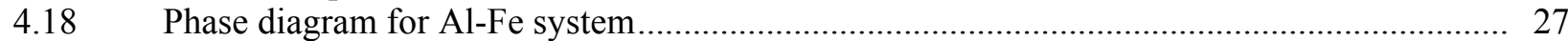

4.19 Solidification path traced using calculations based on Scheil assumptions .......................... 28

4.20 Percentage weight change (normalized against initial weight) of the substrate and the laser processed samples

4.21 Scanning electron micrograph of two samples oxidized in air at $900^{\circ} \mathrm{C}$ for $180 \mathrm{~min}$ :

(a) 4340 steel sample; (b) 1250-W sample.

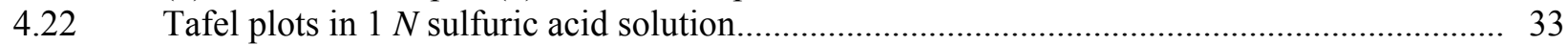

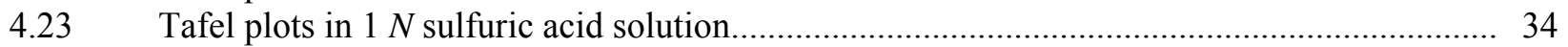





\section{List of Tables}

2.1 Improvement in component life for various industries and resulting savings in steel production based on outcome of proposed work ............................................................... 5

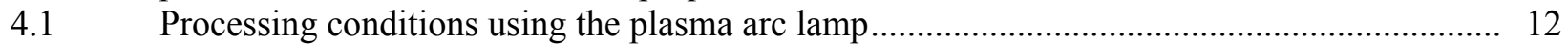

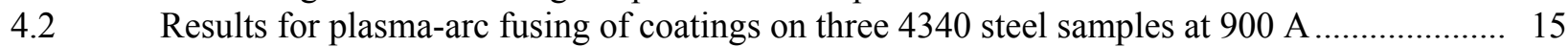

4.3 Weight change as function of time during air oxidation of laser-coated 4340 steel coatings

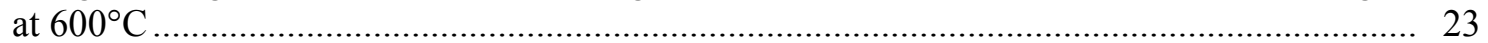

4.4 Oxidation kinetic constants for coatings and substrate at constant temperature $\left(600^{\circ} \mathrm{C}\right) \ldots \ldots \ldots .24$

4.5 Normalized percentage weight gain during isothermal oxidation of the substrate and the

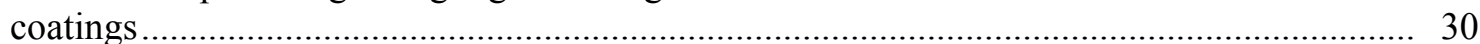

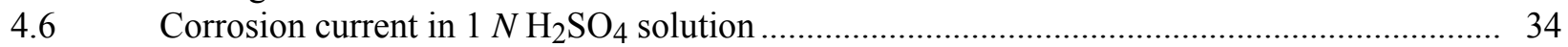

4.7 Corrosion current in $1 \% \mathrm{NaCl}$ solution .......................................................................... 34 



\section{Abbreviations and Acronyms}

$\begin{array}{ll}\text { bcc } & \text { body-centered cubic } \\ \text { CLA } & \text { Center for Laser Applications (UT) } \\ \text { CVD } & \text { chemical vapor deposition } \\ \text { DOE } & \text { U.S. Department of Energy } \\ \text { EDS } & \text { energy-dispersive X-ray spectroscopy } \\ \text { EPMA } & \text { electron probe micro analyzer } \\ \text { FIB } & \text { focused ion beam } \\ \text { HDI } & \text { high-density infrared } \\ \text { IPC } & \text { Infrared Processing Center (ORNL) } \\ \text { IR } & \text { infrared } \\ \text { LPIASM } & \text { laser and plasma-infrared assisted surface modification } \\ \text { OCP } & \text { open circuit potential } \\ \text { ORNL } & \text { Oak Ridge National Laboratory } \\ \text { PVD } & \text { physical vapor deposition } \\ \text { SCE } & \text { saturated calomel electrode } \\ \text { SEM } & \text { scanning electron microscope/microscopy } \\ \text { TEM } & \text { transmission electron microscope/microscopy } \\ \text { TGA } & \text { thermogravimetric analysis } \\ \text { UT } & \text { University of Tennessee } \\ \text { WDS } & \text { wavelength-dispersive X-ray spectroscopy } \\ \text { XRD } & \text { X-ray diffractometry }\end{array}$





\section{Executive Summary}

\subsection{Research and Development}

The project reported here involved development of techniques and materials systems for applying coatings on ferrous (steel) and nonferrous (aluminum-alloy) structural alloys to improve high-temperature wear and susceptibility to corrosion. The coatings used were ceramic-based $\left(\mathrm{TiC}\right.$ and $\left.\mathrm{TiB}_{2}\right)$ and intermetallic (Fe-Al) materials systems. Laser-based and plasma infrared (IR)-based techniques were developed to deposit these coatings on metal substrates. The use of laser, plasma IR, and combination techniques allows a selective coating of various surface geometries and the generation of novel and nontraditional microstructures within the coating and subsurface regions. By controlling the processing parameters during laser and IR processing, various thermal conditions ranging from equilibrium to nearor nonequilibrium can be achieved to tailor the microstructure and the chemical and physical properties of the coatings.

We investigated processing methods as a function of materials and processing parameters such as type of material, energy density, mode of deposition of energy (pulse vs continuous), and speed. The microstructures within the modified surface and the interface (between the modified surface and the substrate) were characterized. Computational modeling based on thermodynamic calculations for the evolution of phases during coating allowed the prediction and design of microstructure as function of processing conditions. The functionality and effectiveness of the coatings produced with experimental and theoretical approaches were evaluated through testing for dry sliding block-on-disc wear tests, hightemperature furnace exposure oxidation tests, thermogravimetric analysis (TGA), dynamic weight change oxidation tests, and potentiometric aqueous corrosion tests. These evaluations indicated that these coated materials showed substantial improvement over the substrate in wear, oxidation, and corrosion performance. Coating inexpensive substrate materials (steel and aluminum) with high-performance material systems is a highly economical approach to producing improved and efficiently performing structural materials for a broad range of applications (e.g., hydro turbines, heat exchangers, die casting dies and inserts, continuous steel casting rolls, transfer rolls for flat glass, cutting and casting tools, combustion chambers in diesel engines, components for chemical processes, components for processing of pulp and paper, and auto engines). The improved and longer-lasting performance of these surfacemodified materials in a wide variety of applications has tremendous potential for energy savings (up to $250 \times 10^{12} \mathrm{Btu} /$ year). Although there was interest in the implementation of these materials systems and processing (engineering) techniques from industrial organizations in various sectors, the time and funding limitations for this project did not allow inclusion of commercialization efforts.

The specific observations of the present project were as follows:

1. Plasma arc high-density IR (HDI) lamps can be used to coat Fe-Al alloys onto 4340 steel. Process conditions and the composition of the precursor coating must be carefully selected to retain iron aluminides on the surfaces of the samples. Under appropriate processing conditions, this technique produces coatings free of porosity and cracks.

2. The hardness of the coating and the heat-affected zone are a strong function of the processing parameters and hence can be tailor-made for an application. In the case of the samples processed with the IR plasma arc lamp, the hardness varied with the processing conditions. Processing conducted at a lower energy density $\left(2025 \mathrm{~W} / \mathrm{cm}^{2}\right)$ with the IR lamp produced harder coatings $\left(>1.5\right.$ times harder) than did processing at a higher energy density $\left(2350 \mathrm{~W} / \mathrm{cm}^{2}\right)$. Similar trends for coating hardness were observed with the use of laser-based techniques. The hardness values within the coating were much larger (Knoop hardness values $>400$ ) than those obtained for the base material (Knoop hardness values $<300$ ). Also, laser processing conducted at higher power 
$(1750 \mathrm{~W})$ produced coatings of lower hardness than did processing at lower power $(1200 \mathrm{~W})$. Thus, both IR- and laser-processed coatings produced at lower energies showed higher wear resistance than coatings produced at higher energies. The evolution of intermetallic compounds (stoichiometry) during the coating process was considered to be responsible for these changes. At higher processing energies, the coating was observed to be rich in aluminum compared with coatings processed at lower energies, thereby providing inferior hardness and wear properties.

3. The better corrosion resistance of the laser-coated Fe-Al as compared with the base steel may be due to the superior oxide layer offered by mixed oxides. The aluminide in the composite coating was responsible for reducing corrosion and oxidation. The variations in corrosion currents and oxidation resistance clearly indicate the influence of processing parameters in improving corrosion resistance. The Fe-Al-coated samples exhibited significantly lower corrosion current $\left(\mathrm{I}_{\text {corr }}\right)$ in both sulfuric acid and sodium chloride solutions. The corrosion current roughly translates to corrosion rate. In other words, the samples coated by the laser technique are significantly more corrosion-resistant than the base materials.

4. Experiments involving oxidation in air, performed with TGA, indicated that laser-processed samples were more oxidation-resistant than were substrates. All the time-weight gain/area relationships were either cubic (in most cases) or parabolic. In other words, there is some degree of intrinsic oxidation resistance in the coating as well as in the substrate.

\subsection{Technology Transfer}

The following publications were based on the results obtained during the project:

G. Muralidharan, P. G. Engleman, C. A. Blue, V. K. Sikka, A. K. Singh, A. Khangar, and N. B. Dahotre, "Laser-Assisted Surface Modification of 4340 Steel with Iron Aluminum Alloys," Proceedings of Materials Research Society (MRS) Symposium, 750, 2003.

G. Muralidharan, C. A. Blue, V. K. Sikka, and N. B. Dahotre, "Surface Modification of 4340 Steel with Iron Aluminides using High-Energy-Density Processes," 2:357-66 in Engineered Steel Surfaces, Proceedings of MS\&T-04, New Orleans, September 2004.

The technical developments and laser-coating processes that grew out of this project were shared with various industrial organizations and universities. A proposal was submitted and later funded based partly on the results of this research. This later project focused on wear components (sieves, screens, and paddles) in the mining industry and involved seven mining companies, two component manufacturers, three industrial outreach organizations, and a university.

\subsection{Commercialization}

In light of these observations and project objectives, we achieved several project goals. We developed reliable, efficient, and economical methods based on high-energy-laser and IR-plasma-lamp processing for coating ceramic and intermetallic materials onto ferrous materials. The techniques developed were proved to be feasible mostly for intermetallic coatings on structural steel (AISI 4340), but their feasibility was also proved for coating ceramic systems such as $\mathrm{TiC}$ and $\mathrm{TiB}_{2}$ on ferrous (steel) and nonferrous (aluminum) metals. The coating microstructures were thoroughly studied to understand their improved response to chemical (corrosion, oxidation) and physical (hardness and wear) stresses as a function of processing parameters. The coating equipment (lasers and IR plasma lamps) was configured to process components of a variety of sizes and shapes and is ready for use in processing industrial components in a production environment. 
The mining project noted in Sect. 1.2 is nearing completion. Industrial trials of laser-coated sieves and screens are showing a $3 \times$ improvement in wear performance in industrial trials.

\subsection{Recommendations}

Based on the findings of this project the following recommendations are made:

- Work on the development of $\mathrm{Fe}-\mathrm{Al} / \mathrm{TiB}_{2}$ coatings for 4340 steel should be supported.

- Further work needs to be performed on developing better processing conditions for coating 4340 steel with Fe-Al.

- A dedicated effort should be made to coat selected important industrial components, and this process should be field-tested. This effort should identify a single industrial sector and target components within this sector for testing. Special consideration should be given to the mining area, since there are many corrosive and wear-intensive operations in this industry. 



\section{Introduction}

In recent years, there has been a considerable increase in the potential and actual uses of certain ceramics and metals for structural, chemical, electrical, and electronic applications in which strength, corrosion resistance, electrical conductivity, and stability in high temperatures are basic requirements. Major applications for ceramics and metals with these properties include hydro turbines, combustion chambers in diesel engines, die casting dies and inserts, continuous steel casting rolls, transfer rolls for flat glass, heat exchangers, cutting and casting tools, components for chemical processes, components for processing of pulp and paper, and auto engines. Effective and efficient performance in these applications requires that different components coexist and form the system as a whole. The integration of hybrid parts with ceramic-metal systems into existing engineering designs can significantly enhance the performance of components. In addition, because of physical and economic limitations, the fabrication of large, complex-shaped components out of a single type of ceramic or metal is often expensive and unnecessary. Based on these requirements, surface modification technology is critical for many structural applications.

Improved wear resistance and corrosion resistance will extend the life of components used in various industries. Table 2.1 lists the estimated improvement in component life and annual savings in steel production (tonnage) for a several components with enhanced wear and corrosion resistance. In addition to extending component life, industrial processing efficiency will also be enhanced by longer availability of equipment. The total energy use by the U.S. industrial sector is $25 \times 10^{15} \mathrm{Btu} / \mathrm{year}$. Even an improvement of $1 \%$ in process efficiency will result in an energy savings of $250 \times 10^{12} \mathrm{Btu} / \mathrm{year}$.

Table 2.1. Improvement in component life for various industries and resulting savings in steel production based on outcome of proposed work

\begin{tabular}{llccc}
\hline & & Estimated & \multicolumn{2}{c}{ Savings (tons) } \\
\cline { 4 - 5 } \multicolumn{1}{c}{ Industry } & \multicolumn{1}{c}{ Components } & $\begin{array}{c}\text { improvement } \\
\text { in life }\end{array}$ & Steel & Refractories \\
\hline Hydro power & Water turbines & $4 \mathrm{x}$ & 30,000 & - \\
Chemical & Multiple components & $2 \mathrm{x}$ & 50,000 & 3,000 \\
Pulp \& paper & Multiple components & $2 \mathrm{x}$ & 20,000 & 5,000 \\
Steel & Continuous caster rolls & $3 \mathrm{x}$ & 14,000 & - \\
Glass & Transfer rolls & $3 \mathrm{x}$ & 6,000 & 10,000 \\
Mining & Equipment & $4 \mathrm{x}$ & 40,000 & - \\
Aluminum & Die casting dies & $2 \mathrm{x}$ & 20,000 & - \\
Automotive & Cylinder liners & $1.5 \mathrm{x}$ & 20,000 & - \\
\multicolumn{1}{c}{ All industries } & & & 200,000 & 18,000 \\
\hline
\end{tabular}

Surface engineering involves design and modification of the surface and the substrate to provide costeffective performance enhancement that is not possible using either component individually. Companies operating in the global economy are striving to extend the lives of old plants and systems by better engineering in the form of surface treatment of inexpensive materials to provide accurate, repeatable, and uniform properties. Thus, the concept of extending component lifetime through service and repair is rapidly spreading and becoming accepted practice. High-energy-density processing tools such as industrial lasers and IR plasmas, as technologically powerful and unique tools, are in the midst of these developments and offer tremendous potential for the purpose. In light of the need for the U.S. manufacturing industry to reduce energy consumption in order to remain competitive in world market and 
with potential of the proposed research to address these needs, this project (DE-FC07-01ID14248) was funded by the U.S. Department of Energy (DOE) in 2001.

Extending the existing limits of component performance via surface enhancement technology presently appears to be the most suitable and economical technical approach because development of bulk material is prohibitively time-consuming and expensive. Surface modification allows conversion of inexpensive substrate material for high-performance applications without using very expensive bulk alloys. Thus, there is a critical need to develop more suitable and reliable surface modification techniques. The proposed laser and plasma IR-based techniques have operating parameters that can be precisely controlled for generating thermal conditions sufficient to synthesize and/or fabricate a product within the surface and subsurface region of the substrate material while producing both a minimum reaction zone and a minimum impact on the microstructure within the substrate. Through the control of and combination of the processing parameters, these techniques can also be used to tailor the microstructure in and around the interface region between the modified surface and the substrate.

This project was a joint effort by the University of Tennessee (UT) and Oak Ridge National Laboratory (ORNL). Overall coordination of the project was conducted by UT. Professor Dahotre served as the principal investigator and coordinated the technical activities. Dr. Vinod Sikka and Dr. Craig Blue of ORNL were co-principal investigators. Professor Dahotre has been involved in developing laser applications for materials processing in the auto, casting, electronic, manufacturing, and other sectors for the past 20 years. Drs. Sikka and Blue are experts in materials processing and have been conducting several projects in cooperation with industry on IR processing of materials.

Laser-based processing was carried out at the Center for Laser Applications (CLA) at UT, and plasma IR lamp processing was conducted at ORNL's Infrared Processing Center (IPC). The CLA, a center of excellence in the UT system that has been in existence for 20 years, has been involved in numerous technologies related to lasers that have been conceived, developed, and implemented in the commercial and industrial environment. It is a leader in the development and application of laser related technologies. The ORNL IPC is the only center of its kind solely involved in developing materials and processing techniques for industrial applications related to wear and corrosion.

This report presents the results of the work performed under this project. Section 3 describes the state of the art in coating technologies, project objectives, and the approach used to achieve the objectives. Section 4 is devoted to results and discussion, including a description of the approach and methodology used to produce coatings and a characterization of the microstructural, mechanical (hardness and wear), oxidation, and corrosion properties of the coatings. The final sections of the report describe accomplishments and provide conclusions and recommendations. 


\section{Background}

\subsection{State of the Art: Coating Technologies}

Laser- and plasma-energy-assisted surface modification procedures were employed in the present efforts to enhance metallic surfaces with thermal energy to create novel microstructures and surface chemistry modifications by external additives for coating precursors (ceramics and metallic). Metal materials with enhanced surfaces for wear and corrosion resistance have cross-cutting application in most of the industrial production sectors in United States. Applications include hydro turbines, combustion chambers in diesel engines, die-casting dies and inserts, continuous steel casting rolls, transfer rolls for flat glass, heat exchangers, cutting and casting tools, components for chemical processes, components for processing of pulp and paper, and auto engines. In these applications, materials often experience extreme mechanical, thermal, and chemical loading conditions and are expected to perform effectively beyond their current capabilities. The most suitable and economical approach for extending the existing performance limits for these materials is via surface enhancement technology. In addition, surface modification allows the use inexpensive substrate materials instead of very expensive bulk alloys for high-performance applications. Thus, there is a critical need to develop more suitable and reliable surface modification techniques such as the one described here.

Many of the existing surface modification techniques based on coating (physical vapor deposition, chemical vapor deposition, thermal spray, etc.) are either prohibitively time-consuming and expensive or produce coatings with physical and chemical properties that restrict their use to a limited number of applications. When these methods are successful in producing reasonably sound coatings, the coatings are seldom able to withstand the intended high service temperatures $\left(>500^{\circ} \mathrm{C}\right)$. By contrast, the research described in this report emphasized the synthesis of strong modified surfaces and significantly improved the performance of these materials for wear and corrosion applications. The laser- and plasma-IR-based techniques employed in the present work hold tremendous promise in competing with several existing surface modification techniques and may be a viable replacement for them. The fact that laser and plasma IR processing can conducted in air without the need for an environmental chamber provides the flexibility for processing a component of any size and shape. The delivery of laser beams via fiber optics provides the additional flexibility of remote processing. These characteristics combined with precise control of operating parameters produce surface modification with minimal impact on the microstructural, physical, and chemical properties of the substrate. The automation of the techniques has tremendous potential for reliability and repeatability in producing coatings.

\subsection{Project Objectives and Approach}

The following major objectives were set for the project:

- Develop a reliable, efficient, and economical method of coating ceramic on metal using highenergy-density-based techniques. The research was conducted for ceramic systems such as TiC and $\mathrm{TiB}_{2}$ on ferrous (steels) and nonferrous (aluminum) metals.

- Characterize the processed coating-substrate material systems for wear and corrosion properties under various conditions and establish a correlation between coating properties and process parameters.

- Develop an understanding of the chemical, physical, and microstructural transformations taking place in the selected representative systems during high-energy treatment. This knowledge about various transformations is believed to be necessary to subsequently develop highly efficient and cost-effective customized applications for surface protection and modification. 
These objectives were accomplished by performing the following tasks.

\section{Enhance surfaces}

The first task was to create advanced materials through enhancing the surfaces only. At UT this task was carried out using lasers; at ORNL surface enhancement was carried out using the highflux-density plasma IR source. The enhanced surfaces were created with the addition of coating precursor as an external additive. The enhanced surfaces were created for use on ceramic-metal as the core material.

\section{Characterize microstructure and composition of coating and surrounding region} The physical appearance of the coating and coating depth and porosity were characterized using optical and scanning electron microscopy (SEM) combined with digital image analysis.

Microstructural characterizations of the coating region, the interface, and the heat affected zone were also performed by using optical and scanning electron microscopy. The distribution of solute elements in and adjacent to the interface region were analyzed using energy-dispersive and wavelength-dispersive X-ray spectroscopy (EDS and WDS) techniques on the electron microprobe. Since the large heating and cooling rates of the laser-induced-reaction coating technique produce unconventional and nonequilibrium phases which control the mechanical and chemical properties of the coating and the interface, it was necessary to carry out a detailed phase analysis of the coated sample. Phases were analyzed by X-ray diffractometry (XRD) and transmission electron microscopy (TEM). Computational modeling based on thermodynamic calculations for phase evolution during coating was conducted for the prediction and design of the microstructure as a function of processing conditions.

\section{Evaluate wear, oxidation, and corrosion behaviors}

The wear behavior of the coated samples was studied by employing the block-on-disk tribometer under dry sliding conditions at room temperature. The weight loss measurements were conducted under different sliding speeds and normal loads. Even though the tribometer is not equipped to provide measurements in high-temperature and lubricating environments, these limited measurements under dry sliding conditions at room temperature, supplemented with high temperature-corrosion results, would provide substantial data to predict the wear behavior of the coatings at elevated temperatures. High-temperature furnace exposure oxidation tests, TGA dynamic weight change oxidation tests, and potentiometric aqueous corrosion tests were conducted on the coated samples.

\section{Assess data and prepare report}

The assessment of the data and development of recommendations for future efforts were done in the quarterly meetings of the participating individuals either at ORNL or at UT-Knoxville. These meetings also were used to provide guidelines for quarterly reports to be prepared and submitted to DOE. 


\section{Results and Discussion}

\subsection{Literature Review}

Many problems exist in the synthesis and fabrication of ceramic-metal surfaces. In general, the constituents of such systems have substantial differences in properties such as modulus of elasticity, coefficient of thermal expansion, and thermal diffusivity. Therefore, large thermally induced mechanical stresses are set up in the interface regions. In the past, this problem was circumvented, though with limited technical or commercial success, through techniques such as diffusion coating, functionally gradient coating, and bond coatings via physical vapor deposition (PVD) [1-3], chemical vapor deposition (CVD) [4-7], thermal spraying [8-11], and weld overlay [12-13] techniques. Techniques such as diffusion coating have proven useful for producing coatings with good elevated-temperature properties. Because both PVD and CVD frequently require environmental chambers, their practicality is limited. They are also prohibitively time-consuming and expensive because they rarely produce coatings with thicknesses $>50 \mu \mathrm{m}$. Thermal spraying provides a thicker coating $(\leq 1000 \mu \mathrm{m})$, but the coatings produced by this technique can have high porosity and a weak interface with the substrate. The weld overlay technique is most economical for producing layers $>1 \mathrm{~mm}$ thick; however, the process creates potentially critical conditions. The material at the interface is superheated for a long time, resulting in accelerated reaction rates between different ceramics and substrates, and leading to extensive interdiffusion of species. This situation results in the formation of an entirely different microstructure with degraded mechanical and chemical properties. In addition, the relatively large heat source in these processes melts a large volume of the base materials, producing a coarse grain structure.

Thus, there remains a critical need to develop methods that can produce modified surfaces with thicknesses in the range of $100 \mu \mathrm{m}$ to $1 \mathrm{~mm}$ that are suitable for large components and field applications, and that can produce structurally modified surfaces and/or coatings for use at elevated temperatures. Such methods would have tremendous potential for commercialization.

One approach to producing such modified surfaces and coatings is the use of a high-energy-density laser [14-37] and plasma IR [38-39] assisted surface modification (LPIASM). The recent advent of the multikilowatt laser with a fiber optic beam delivery system and IR lamps of various physical geometries mounted on a manipulator makes it possible to develop a versatile, multipurpose surface modification process. The most important advantage of LPIASM over other surface modification and coating techniques stems from the fact that LPIASM involves high cooling rates $\left(10^{3}-10^{8} \mathrm{~K} / \mathrm{s}\right)$ and high energy densities $\left(>3 \mathrm{~kW} / \mathrm{cm}^{2}\right)$, which produce metastable phases by exceeding the solid solubility limit beyond equilibrium phase diagram prediction. This technique can lead to the development of a wide variety of microstructures with novel properties that cannot be produced by any conventional processing technique. Thus, LPIASM can produce modified surfaces with unique thickness ranges, material properties, and microstructures.

A review of the technical literature reveals few efforts to use integrated LPIASM for modifying surfaces to achieve a layer thickness $>100 \mu \mathrm{m}$. Therefore, the long-term goal of this project was to develop the LPISAM technique to synthesize and fabricate novel material systems for reliable, repeatable, and costeffective performance in commercial environments.

\subsection{Technical Approach and Hypothesis}

The proposed approach involves synthesis and/or fabrication of the modified surface via chemical, microstructural, and physical transformation in a controlled manner using external heating provided by a 
high-energy-density laser beam and/or a plasma IR heat source. Localized heating of the precursor (elemental or alloy or molecular) deposited surface by the laser beam or the plasma IR heat source will initiate a chemical transformation, which will further be sustained to synthesize reaction products at the interface between the modified surface region and the substrate, resulting in chemical interaction and bonding. Such a technique can appropriately be described as a laser- and plasma IR-assisted surface modification (LPIASM) process. The proposed research is designed to prove the feasibility of the technique for the synthesis and fabrication of ceramic, composite, and metal-based modified surface layers on ferrous and nonferrous materials.

With LPIASM, unlike many other surface modification techniques, precise control over processing parameters allows creation of thermal conditions suitable for promoting controlled reactions between the substrate material and the precursor material to aid in increasing the surface energy and wettability of substrates via formation of different products at the interface. In addition, in LPIASM the action of powerful energy fluxes delivered by a laser and/or IR source at a convenient location eliminates the need to heat a large volume of the material system by an external heat source, thereby avoiding damage to the whole structure. This is particularly useful in critically thin sections or with geometries that have complicated topographies. The rapid rates of heating and cooling in a narrow interaction region result in the formation of nonequilibrium and unconventional phases at the interface, and prevent recrystallization of grains within both the substrate and the modified surface. This ensures that strengths are maintained. Through the appropriate selection and control of precursor mixtures and processing parameters (such as continuous wave mode, pulse tailoring technique, beam power, and traverse speed), LPIASM can be tailored to synthesize and fabricate materials in the surface region that are physically and chemically compatible with a wide variety of ceramic or metal substrate systems.

Mathematical modeling can provide further insight into the synthesis and fabrication of laser and plasma IR-modified surfaces crucial for reliability and repeatability in commercial environment. The modeling is based on chemical transformations and microstructures during LPIASM and also takes into account important laser process parameters.

In this project, the greatest challenges were more scientific than technological. They included developing the fundamental basis for correlating microstructural, chemical, and physical changes with process parameters and wear and corrosion properties. In light of this, the main targets included systematic evaluation of microstructural changes in relation to process parameters and wear and corrosion properties.

\subsection{Experimental Methodology, Test Procedures, and Characterization Methods}

\subsubsection{High-Energy-Density Processing: Infrared Plasma Arc Lamp and Laser}

IR plasma arc processing was done at the Infrared Processing Center at ORNL. The IPC houses the most powerful plasma arc lamp in the world, producing the extremely high power density of $3.5 \mathrm{~kW} / \mathrm{cm}^{2}$ in a single lamp (see Fig. 4.1). Instead of utilizing a resistive element to produce IR, controlled and contained plasma is utilized. The plasma arc lamp consists of a 3.175-cm-diam-quartz tube, which can be 10,20, or $35 \mathrm{~cm}$ long. The lamp is sealed at the ends where the cathode and anode are located. Deionized water mixed with argon or nitrogen gas enters at the cathode side via high-velocity jets impinging at a given angle. Due to the high velocities and pressure, the deionized water separates to the wall of the quartz and spirals down the length of the quartz in a uniform 2- to 3-mm film. This water film serves two purposes: (1) cooling the quartz wall and (2) removing any tungsten particulate that may be expelled from the cathode. The gas moves in a spiral fashion down the center of the tube, and a plasma initiation device strikes the plasma. The plasma is stable and produces an IR spectrum from 0.2 to $1.4 \mu \mathrm{m}$, similar to natural sunlight in energy distribution and color rendition. The color temperature of the lamp is in excess of $10,000 \mathrm{~K}$. Powder coatings in this study are highly absorbing due to the open structures and behave like small black bodies. The lamp has a typical life of approximately $1200 \mathrm{~h}$, and failure occurs in the 


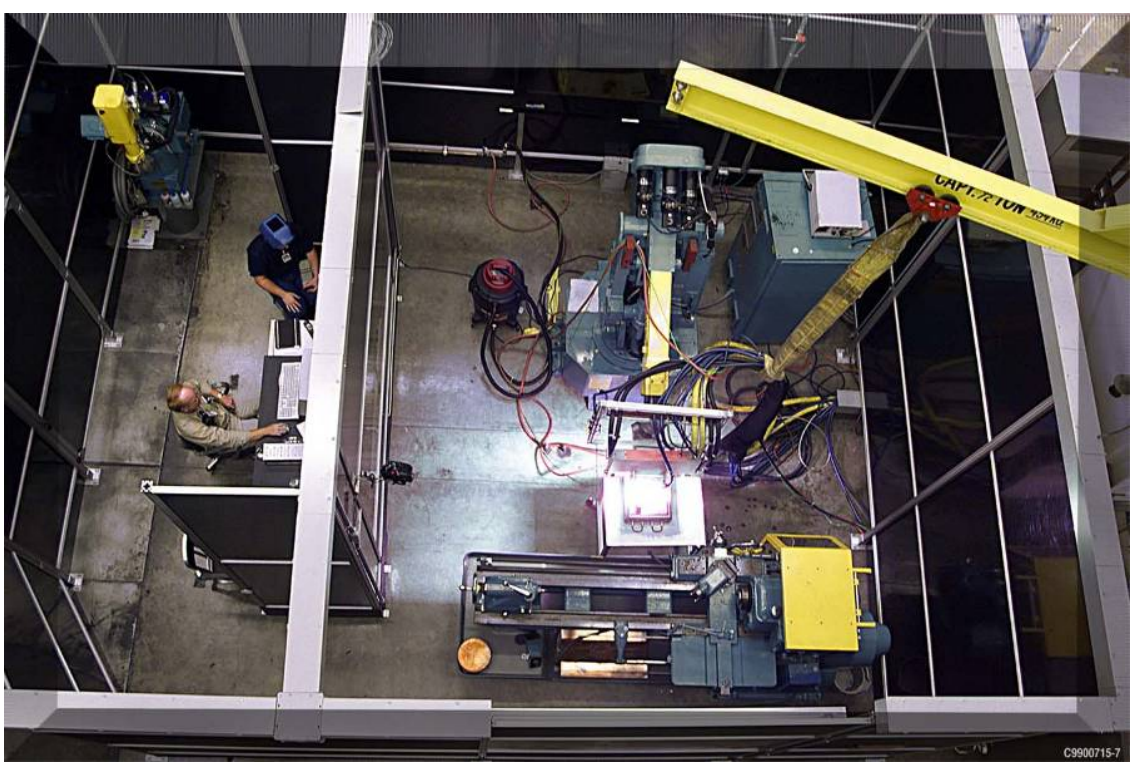

(a)

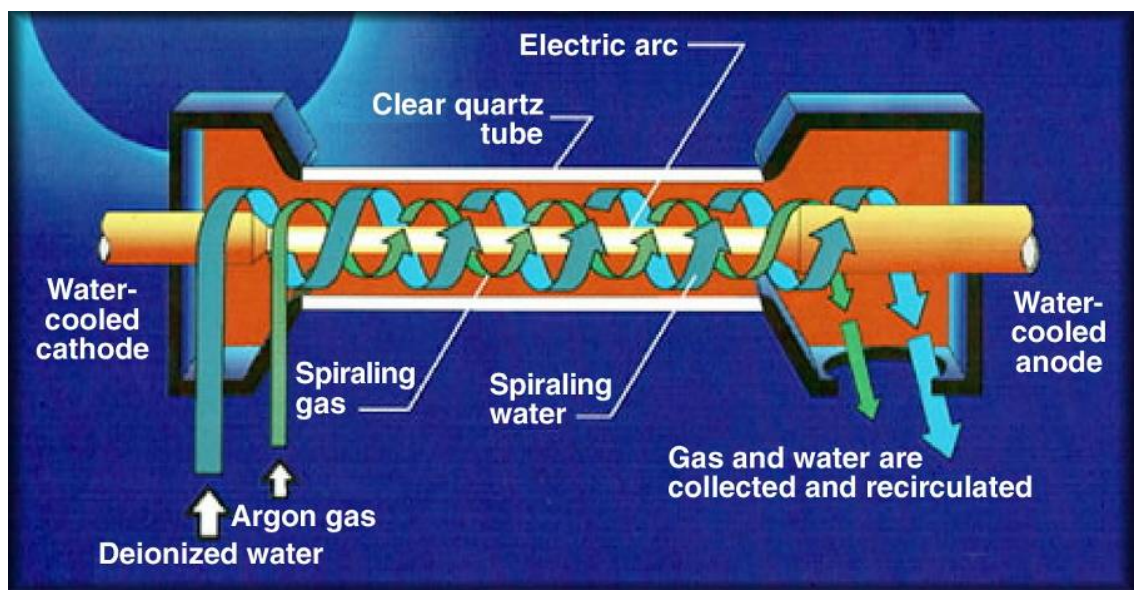

(b)

Fig. 4.1. Control room and 3.5-kW plasma arc lamp at ORNL's Infrared Processing Center. (a) Top view of the control room and lamp; (b) diagram of the plasma arc lamp showing the quartz tube with an internal water wall and direct-current argon plasma.

anode or cathode. These parts are inexpensive and can be changed in approximately $15 \mathrm{~min}$. The lamp has a consistent spectral output independent of lamp life and power level. Thus, the process coating will always be impinged upon with an identical IR spectrum. The lamp is typically configured with a line focus or a uniform irradiance reflector.

Processing was performed with the sample placed in an environmentally controlled box with an IRtransparent quartz cover. In this work, the IR plasma arc lamp was used to synthesize coatings. The processing conditions used were as shown in Table 4.1. 
Table 4.1. Processing conditions using the plasma arc lamp

\begin{tabular}{ccc||ccc}
\hline Trial \#1 & Power & Scan speed & Trial \#2 & Power & Scan speed \\
\hline First scan & $2025 \mathrm{~W} / \mathrm{cm}^{2}$ & $8 \mathrm{~mm} / \mathrm{s}$ & First scan & $2025 \mathrm{~W} / \mathrm{cm}^{2}$ & $6 \mathrm{~mm} / \mathrm{s}$ \\
$\begin{array}{c}\text { Second scan } \\
\text { (immediate) }\end{array}$ & $2350 \mathrm{~W} / \mathrm{cm}^{2}$ & $8 \mathrm{~mm} / \mathrm{s}$ & Second scan & $2350 \mathrm{~W} / \mathrm{cm}^{2}$ & $8 \mathrm{~mm} / \mathrm{s}$ \\
\hline
\end{tabular}

A 3.5-kW Hobart HLP $3000 \mathrm{Nd}$ :YAG laser that generates an intense coherent monochromatic beam of $1.06 \mu \mathrm{m}$ was employed in the present work. ${ }^{1}$ The laser can operate in continuous and pulse modes. It is equipped with a $600-\mu \mathrm{m}$-diam, 17-m-long fiber optic for beam delivery. The fiber is interfaced with an end effector that houses a set of spherical and cylindrical lenses. A combination of cylindrical and spherical lenses is put together to shape the laser beam output into a line configuration $(6 \mathrm{~mm} \times 600 \mu \mathrm{m})$ with dumbbell-shaped energy distribution. In the spatial mode, the high-energy lobe at two ends of the line beam compensates for rapid heat conduction (loss) to the surrounding material along the edges of the track and produces uniform thermal effects within the track. Such a line beam, with a unique energy distribution permits processing with minimal or no overlap between the successive passes. The laser is also equipped with $10-\mathrm{ft}$ linear-motion work station. The laser operation and beam and workpiece motion are controlled by an integrated PC-based system. The fiber-optic-based beam delivery provides the added capability of traversing the beam on components of various shapes and sizes, thereby making it suitable for industrial processing. In this project, we used several sets of processing parameters that were optimized in accordance with our earlier experience. For one set of processing parameters we kept the laser beam power and the traverse speed constant at $2 \mathrm{~kW}$ and $100 \mathrm{~cm} / \mathrm{min}$, respectively, while for the other set of processing parameters, we used three different laser power settings-1250 W (low), $1500 \mathrm{~W}$ (medium), and $1750 \mathrm{~W}$ (high) — with the travel speed kept constant at $220 \mathrm{~cm} / \mathrm{min}$.

\subsubsection{Materials}

The selection of the coating composition depends upon the composition of the substrate to be coated and the method to be employed. In the present effort, several coating precursors were investigated.

Commercially available (99.5\% pure) $\mathrm{TiC}$ and $\mathrm{TiB}_{2}$ powders from CERAC (Milwaukee, WI) were used as precursor in some of the studies. The average particle size was $10 \mu \mathrm{m}$. The precursor, in a water-based organic vehicle (hydroxypropyl methyl cellulose), was sprayed on the substrate coupons using a manual spray gun. The average thickness of the preplaced powder (precursor) was $150 \pm 15 \mu \mathrm{m}$ for $6061 \mathrm{Al}$ and $90 \pm 15 \mu \mathrm{m}$ for 4340 steel. Sprayed coupons were dried at $70^{\circ} \mathrm{C}$ for $1 \mathrm{~h}$ prior to laser processing.

In addition, we also synthesized coatings of intermetallic materials. Argon gas-atomized FeAl alloy powder [Fe-41.7Al-0.18Mo-0.04Zr-1.1C-0.02B (at. \%)], -100 mesh particle size, was mixed with pure aluminum powder, resulting in an overall compositions of $75 \mathrm{~mol} \% \mathrm{Al}$ in the FeAl-Al mixture. Another composition included $75 \mathrm{~mol} \% \mathrm{Al}$ in the FeAl-Al mixture seeded with $15 \mathrm{vol} \% \mathrm{TiB}_{2}$. These mixtures were subsequently blended with a water-based organic binder (hydroxypropyl methyl cellulose) and sprayed as a precursor coating onto coupons of 4340 steel [nominal composition: Fe-1.8C-0.74Cr- $0.7 \mathrm{Mn}-$ 0.11Mo-1.7Ni-0.39Si (at. \%)] using a manual spray gun.

\subsubsection{Test Procedures and Characterization Methods}

Tests and analyses of coated samples were performed using optical microscopy, SEM, and TEM; electron probe microanalysis; XRD microhardness and wear testing; oxidation evaluation; and corrosion testing. The details of these test and characterization methods are provided in the following sections.

\footnotetext{
${ }^{1}$ A 3.2-kW Rofin Sinar R3000 with identical beam characteristics was used to process samples during a brief period when the Hobart laser was being serviced. Samples were processed under the same conditions (power and speed) with both lasers.
} 


\section{Microscopy}

Topographical and cross-sectional observations were made on the processed samples after the steel samples were etched with 2 vol \% Nital, and the aluminum samples, with Kellings reagent. Surface morphology was evaluated using a Hitachi-3500 SEM (Hitachi, Tokyo, Japan). A CAMBEX electron probe micro analyzer (EPMA) operated at $25 \mathrm{kV}$ was employed to analyze the cross-sectioned samples for the variation in composition as a function of position within the coating and the substrate.

Both the mechanical and the chemical performance of coatings are influenced by the interface between various phases within the coating as well as the substrate and coating. Microstructural evaluations of these interfaces can best be conducted by TEM analysis. TEM analysis was conducted using a Hitachi 800 microscope operated at $200 \mathrm{kV}$. The coating thicknesses achieved were less than $500 \mu \mathrm{m}$. In addition, these coatings are relatively harder and more brittle than the substrate material. The thickness and hardness of the coatings pose complex problems when preparing TEM samples from the coating region using conventional techniques such as electropolishing and ion beam milling. Both techniques require mechanical cutting, grinding, and polishing for preparation of submillimeter-thick foil samples for further electropolishing or ion milling to achieve thin enough samples for TEM observations. The mechanical treatment in preparation of samples often leads to cleavage damage in harder samples, and electropolishing and ion milling are extremely time-consuming and unreliable means for providing good samples. Moreover, the coatings often undergo differential ion/electrochemical thinning.

In view of these shortcomings, we adopted the newly developed focused ion beam (FIB) milling and liftout technique, which utilizes a $30-\mathrm{kV} \mathrm{Ga}^{+}$ion beam to extract electron transparent specimens with nanometer-scale precision. The FIB lift-out technique is especially suitable for ceramic and FeAl coatings, as it allows sample extraction from extremely small volumes of unpolished material from a site at the submicrometer scale without introducing any artifacts of mechanical preparation. FIB milling was performed with an FEI Model 200 TEM FIB system at the University of Central Florida.

\section{Phase Identification and Hardness and Wear Testing}

We used a Philips Norelco X-ray diffractometer operated at $30 \mathrm{kV}$ and $20 \mathrm{~mA}$ to characterize the starting precursor coating powders as well as the coatings with $\mathrm{Cu} \mathrm{K} \alpha$ radiation. The diffraction range was from $20^{\circ}$ to $100^{\circ}$, with a step increment of $0.02^{\circ}$ and a count time of $1 \mathrm{~s}$. These observations were supplemented with microhardness tests (Knoop hardness, $100 \mathrm{gm}$ normal load, $15 \mathrm{~s}$ loading time). X-ray diffraction measurements were carried out to identify phases present in the samples. We studied the effect of processing on wear resistance using a block-on-disk tribometer under dry sliding conditions. Coated coupons were tested for dry sliding wear against a hardened steel ring rotating at a linear speed of $4.6 \mathrm{~m} / \mathrm{s}$. Weight loss measurements were made after successive 2-min intervals. Wear tests were conducted for a total of $10 \mathrm{~min}$ with a normal force of $50 \mathrm{~N}$.

\section{Oxidation Testing}

The kinetics and mechanism of oxidation were evaluated by exposing samples in a resistance furnace. These oxidation studies also helped estimate the long-term oxidation response. The coupons were sectioned along the interface between the coating and the substrate on a slow-speed diamond-laced wheel machine. This process provided stress-free sections of the coating $(\sim 500 \mu \mathrm{m}$ thick), which were then cut into smaller samples of $5 \times 5 \mathrm{~mm}$. Samples having similar dimensions were also cut out from the substrate material (4340 steel) for performance comparisons. These samples were exposed to air at a constant temperature of $600^{\circ} \mathrm{C}$ inside an electric resistance box furnace. Initially, it was decided that weight change measurements will be conducted for the time durations of $120,240,480$, and $960 \mathrm{~h}$. However, because of very slow oxidation kinetics (high oxidation resistance), weight changes are reported only for time durations of 120 and $504 \mathrm{~h}$. 
In order to conduct oxidation studies at various holding temperatures, TGA studies were undertaken for the coating and the substrate. The coating alone cannot be directly heated in the furnace, as the weight gain due to oxidation of substrate would shadow the coating. Hence, the substrates were carefully machined from the coating, giving a thin layer of about $100 \mu \mathrm{m}$. The resulting samples were essentially the composite microstructure formed in laser processing. The TGA study was conducted at temperatures of 500, 700, and $900^{\circ} \mathrm{C}$ in air. The TGA furnace was heated at a rate of $10^{\circ} \mathrm{C} / \mathrm{min}$ with a hold time of $3 \mathrm{~h}$, followed by cooling at a rate of $10^{\circ} \mathrm{C} / \mathrm{min}$. The weight change as function of time was constantly recorded during the entire time of exposure.

\section{Corrosion Testing}

The aqueous corrosion performance of the coated sample was evaluated using potentiometric measurements. Tafel calculations based on these measurements give the corrosion current regularly present on the surface of a metal that is in contact with a corroding solution [40-41]. Corrosion is expressed in loss of metal thickness per year. The Tafel method also provides other corrosion parameters such as the zero current potential (corrosion potential) and the polarization resistance of the sample. Thus, the Tafel method is an excellent approach to studying the corrosion process on a metal surface.

In the current study we subjected laser-processed samples to corrosion to obtain Tafel measurements. Rectangular samples $(10 \times 10 \mathrm{~mm})$ were cut from the coated samples. These specimens were directly polished (without prior grinding with emery paper), using an alumina slurry $(0.05 \mu \mathrm{m})$ suspension, on velvet cloth to remove the oxidized layer and dirt and contamination from the specimen's surface. Before polarization, the samples were ultrasonically cleaned with acetone solution. Anodic polarization and Tafel curves were recorded in the $1 \mathrm{~N}$ sulfuric acid and $1 \% \mathrm{NaCl}$ solutions. These solutions were prepared by adding $\mathrm{AR}$ grade sulfuric acid and $\mathrm{NaCl}$ crystals to distilled water. Anodic polarization curves were initiated from $-300 \mathrm{mV}$ with respect to open circuit potential (OCP). However, the Tafel plots were initiated from $\pm 250 \mathrm{mV}$ with respect to OCP. Both anodic polarization and Tafel plots were carried out at a scanning rate of $6 \mathrm{~V} / \mathrm{h}$. The saturated calomel electrode (SCE) was used as the reference electrode and platinum as a counter electrode. The experiments were carried out at ambient temperature.

\subsection{Presentation and Discussion of Results}

Two widely used materials served as substrates: a medium-carbon, ultrahigh-strength, low-alloy steel (AISI/SAE 4340) and a heat-treatable aluminum alloy (6061-T651). According to the ASM Metals Handbook, 4340 steel is considered the standard by which other ultrahigh-strength steels are measured. It combines deep hardenability with high ductility, toughness, and strength. Typical applications include fasteners; gears, shafts, and crankshafts for engines; and critical structural members for aircraft. Aluminum alloy 6061 is used in applications where good strength, formability, weldability, and resistance to corrosion are required. Typical applications include bridge railings, marine applications, and transportation equipment.

\subsubsection{IR Coating}

The coatings on three 4340 steel samples were fused using the IR plasma lamp process at ORNL at different current levels and processing times. Table 4.2 summarizes the conditions and results.

As the table indicates, the first alumina-coated sample was passed two times under the plasma-arc lamp. The alumina in this sample melted, as evidenced by a glassy surface, but the coating did not adhere to the steel, spalling off in large pieces upon cooldown. Although the alumina coating on the second sample appeared to have adhered, it was only slightly more adherent than the previous sample. Examination using optical microscopy at magnifications up to $400 \times$ showed that, as expected, the coating on this 
Table 4.2. Results for plasma-arc fusing of coatings on three 4340 steel samples at $900 \mathrm{~A}$

\begin{tabular}{lccl}
\hline Condition & Pass & $\begin{array}{c}\text { Processing } \\
\text { speed } \\
(\mathbf{m m} / \mathbf{s})\end{array}$ & Result \\
\hline 1. Alumina coating & Pass 1 & 10 & Alumina melted; coating did not adhere \\
2. Alumina coating 2 & 5 & Coating adhered slightly more than under \\
& Pass 1 & 10 & condition 1 \\
3. $\mathrm{TiB}_{2}$ coating & Pass 2 & 10 & Coating appeared well adhered but optical \\
& Pass 3 & 5 & microscopy and SEM indicated otherwise \\
\hline
\end{tabular}

sample had undergone more melting due to the third heating pass. The third sample processed with HDI was composed of a coating of $\mathrm{TiB}_{2}$ powder on 4340 steel. In this case, the $\mathrm{TiB}_{2}$ appeared to be tightly adherent to the steel, but examination by optical microscopy and SEM indicated that the coating was not fully dense.

Figure 4.2 shows a cross-sectional optical micrograph of the sample processed using condition 1, and Fig. 4.3 shows the corresponding X-ray diffraction pattern. Analysis of the diffraction pattern shows the presence of FeAl. As in the laser-processed samples, an oxide layer was observed on the surface. A crosssectional optical micrograph of the sample processed using condition 2 is shown in Fig. 4.4, with the corresponding X-ray diffraction pattern shown in Fig. 4.5. Peaks that would indicate the presence of intermetallic compounds were not observed in the diffraction pattern. The only difference between the two sets of parameters (processing conditions 1 and 2) is that in the second set of processing parameters, the scan at the lamp power of $2025 \mathrm{~W} / \mathrm{cm}^{2}$ occurred at a speed of $6 \mathrm{~mm} / \mathrm{sec}$ instead of the speed of 8 $\mathrm{mm} / \mathrm{sec}$ used in set 1 . The slower scan speed resulted in a larger heat input to the sample, thus causing increased dilution and the disappearance of the intermetallic compound.

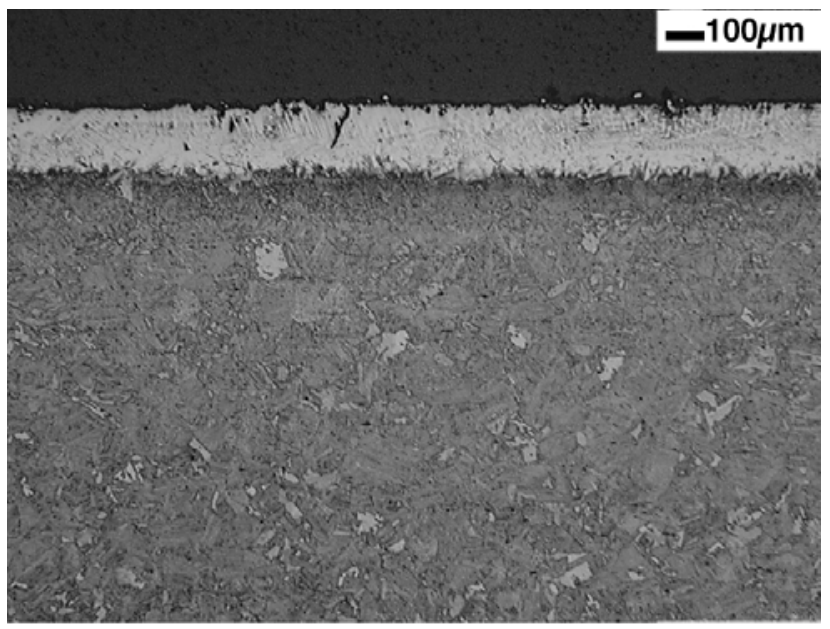

Fig. 4.2. A cross-sectional optical micrograph of a 4340 steel substrate with Fe-Al alloy coating processed with a plasma arc lamp (processing condition 1). 


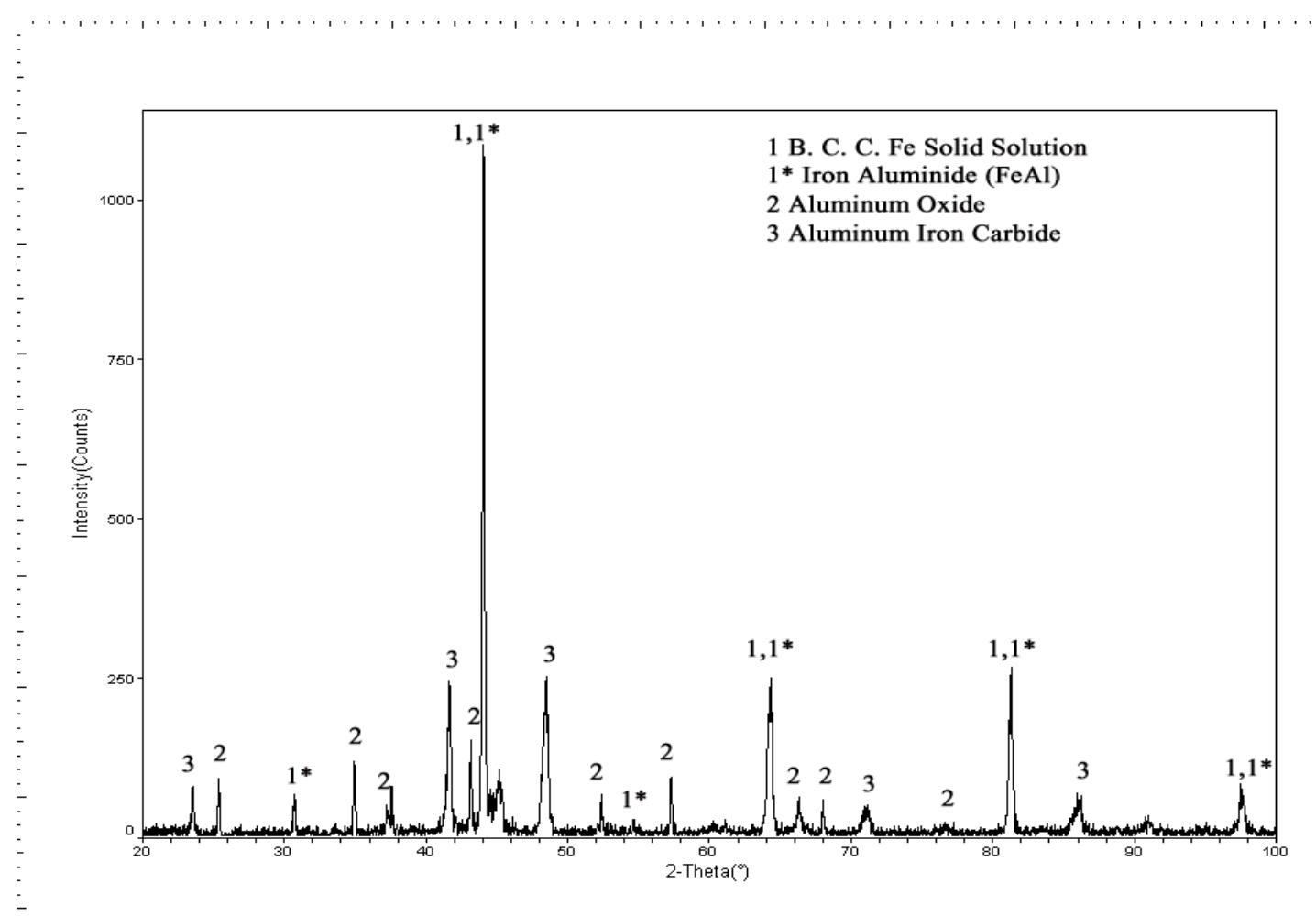

Fig. 4.3. X-ray diffraction pattern from sample processed with a plasma arc lamp (processing condition 1).

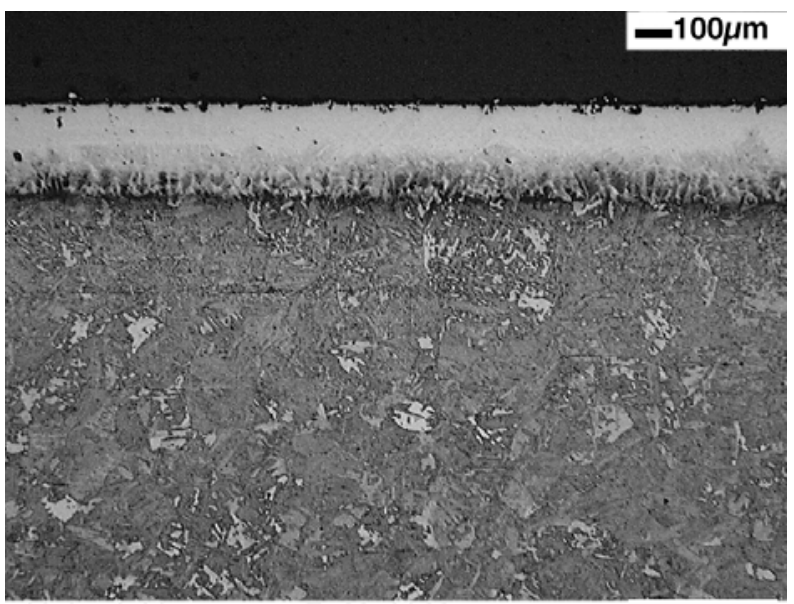

Fig. 4.4. A cross-sectional optical micrograph of a 4340 steel substrate with $\mathrm{Fe}-\mathrm{Al}$ alloy coating processed with a plasma arc lamp (processing condition 2). 


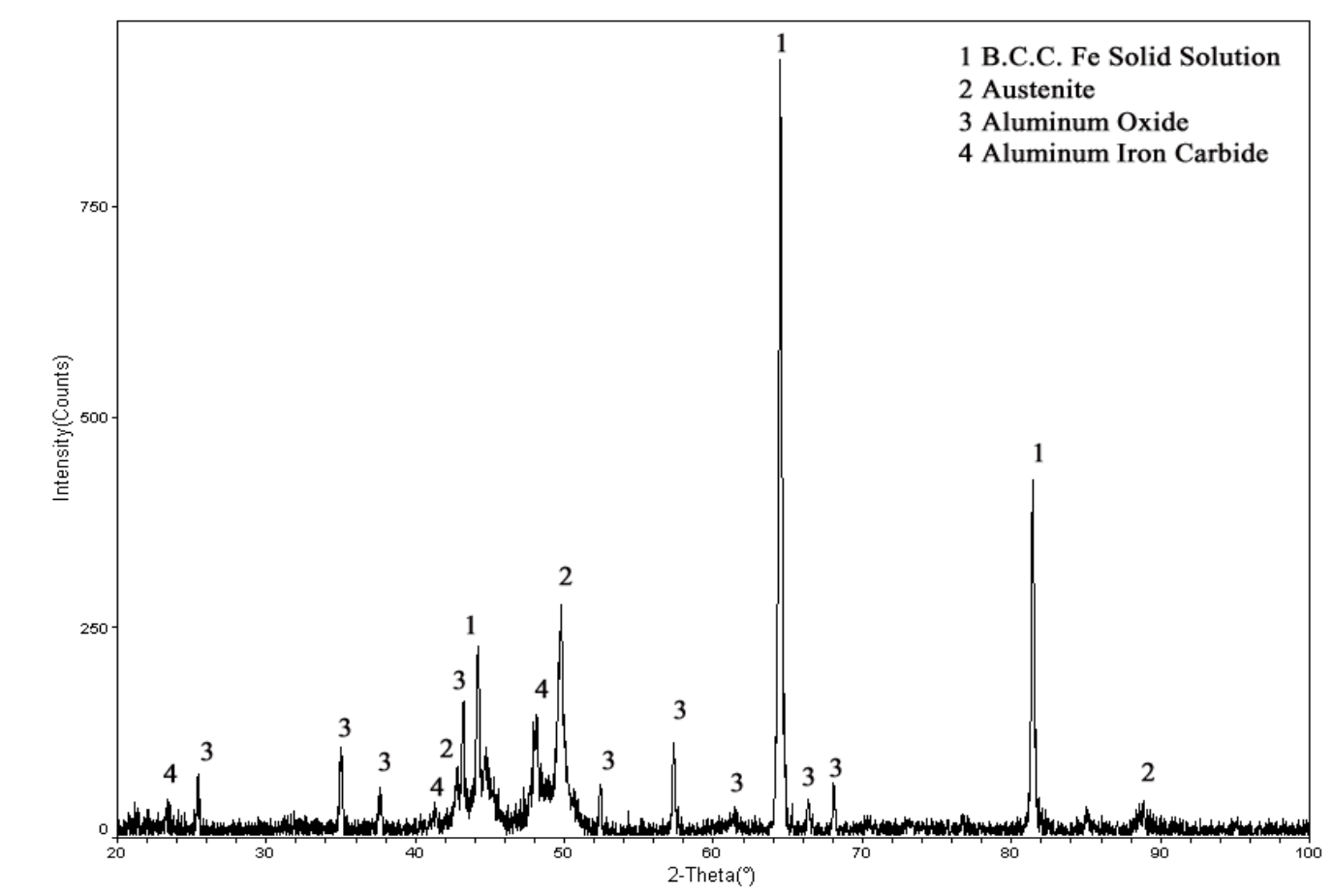

Fig. 4.5. X-ray diffraction pattern from sample processed with a plasma arc lamp (processing condition 2).

Figure 4.6 shows the variation in Knoop hardness values as a function of position within the coating, the heat-affected zone, and the substrate for samples processed using the plasma arc lamp. The hardness values vary with the processing conditions. The sample processed using processing condition 1 reveals hardness values within the coatings layer that are higher than the values for those processed using condition 2. Intermetallic compounds present in the sample processed using processing condition 1 may be responsible for the higher hardness values. A significant feature in both samples processed using the plasma arc lamp is that a region with high hardness occurs at a distance of $\sim 100-300 \mu \mathrm{m}$ from the surface of the sample. The presence of a martensitic region, as observed in previous studies [22-25, 27] of laser processing of steel substrates, results in high hardness values. It should be noted that hardness values were measured at intervals of $50 \mu \mathrm{m}$ only. Any variation over length scales smaller than this would not have been observed.

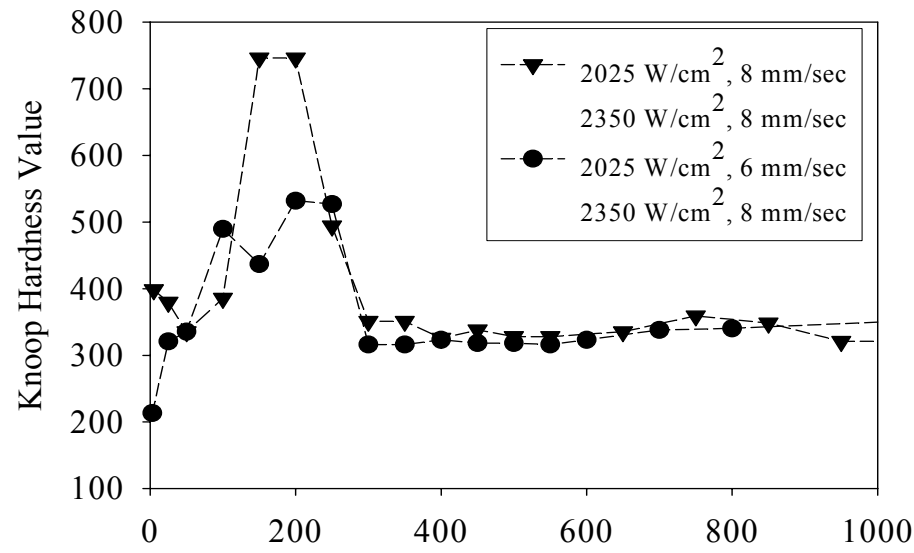

Distance from the Surface $(\mu \mathrm{m})$

Fig. 4.6. Variations in Knoop hardness values as a function of distance perpendicular to the surface and of the process parameters in coatings processed using the plasma arc lamp. 


\subsubsection{Laser Coating}

In light of the observations for plasma arc lamp coating, we explored laser-based coating. Exploratory tests indicated the feasibility of using lasers for coating ceramics on ferrous and nonferrous alloys. Figure 4.7 shows a cross section of two laser-processed samples. In both cases the coating is dense, adherent, and defect-free (with no porosity or cracks). The coating is a composite, with TiC particles in the aluminum matrix and $\mathrm{TiB}_{2}$ particles in the steel matrix. The distribution of ceramic particles in both cases is uniform, indicating better wettability within the selected ceramic-metal systems.
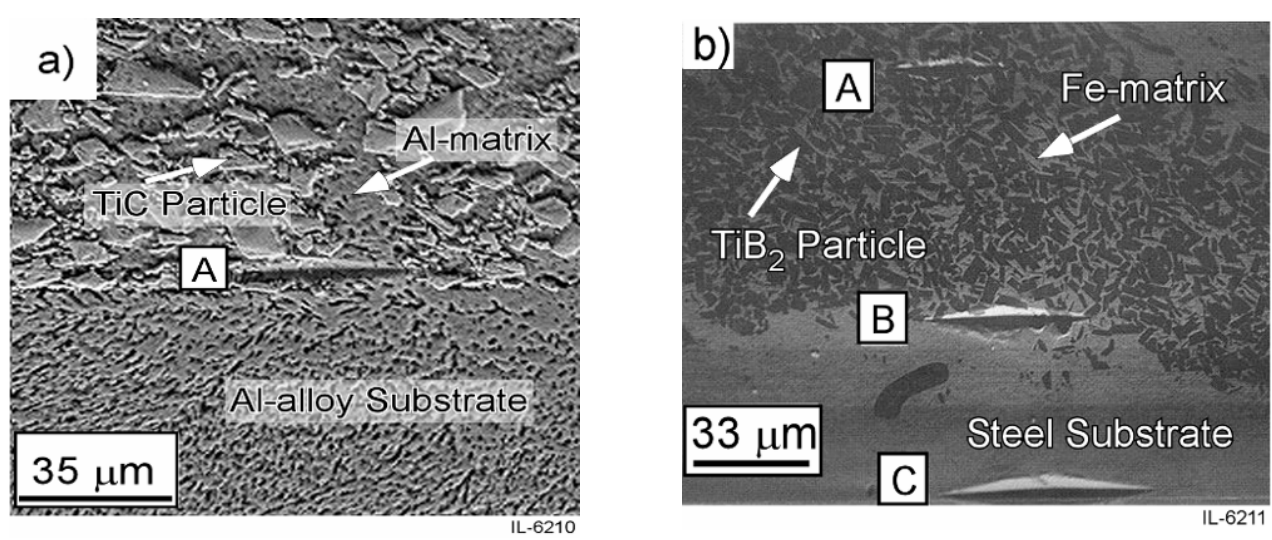

Fig. 4.7. Composite coatings produced using a laser technique: (a) TiClAl composite coating on 6061 aluminum alloy; (b) $\mathrm{TiB}_{2} /$ steel composite coating on 4340 steel. The letters within each micrograph identify hardness indentations.

X-ray diffraction analysis of the TiC-coated 6061 aluminum surface indicated $\mathrm{TiC}$ and aluminum as the major constituents of the coating along with few other minor phases such as $\mathrm{Al}_{2} \mathrm{O}_{3}$ and $\mathrm{Al}_{3.21} \mathrm{Si}_{0.47}$. Similarly, for the $\mathrm{TiB}_{2}$-coated steel surface $\mathrm{TiB}_{2}$ is the major phase, along with small peaks of metastable phases of type $\mathrm{Fe}_{\mathrm{a}} \mathrm{B}_{\mathrm{b}}$ and $\mathrm{Ti}_{\mathrm{m}} \mathrm{B}_{\mathrm{n}}$. The formation of minor quantities of these additional phases in both coatings is attributable to the high energy input combined with a high cooling rate by self-quenching during the laser processing. The formation of these phases can be controlled by controlling the processing parameters.

Hardness testing was performed using a microhardness tester with a Knoop indenter. Hardness values were recorded within the coating and the substrate and along the interface between the coating and the substrate. In all cases, the hardness was substantially higher in the coating $(>3 \times)$ than in the substrate material. Also, the indentation made along the interface did not show any cracking, indicating a coherent and strong interface. Further qualitative evaluations of the interface in various substrate/coating combinations were conducted by making a series of indentations along the interface under increasing normal loads within the range available (50-1000 g). None of the indentations within the range of normal load showed cracking at the interface. These results confirmed the soundness and strength of the bonding (interface) between the coating and the substrate.

As can be seen in the Fig. 4.7, hardness indentations within various regions of the processed samples indicate the relative nature of these regions. It can be clearly seen that size of the hardness indentation within the coating is small compared to the indentation within the substrate, indicating that the coating is substantially harder than the substrate. The lack of the cracking at the end of the indentation along the interface between the coating and substrate indicates that the interface is strong, without any defects.

The strong interface between coating and substrate and the improved hardness in the coating are due in part to the formation of a chemical bond through a reaction zone at the interface, as shown in TEM micrographs in Figs. 4.8 and 4.9. Thus, these efforts to synthesize the coatings and the post-process 

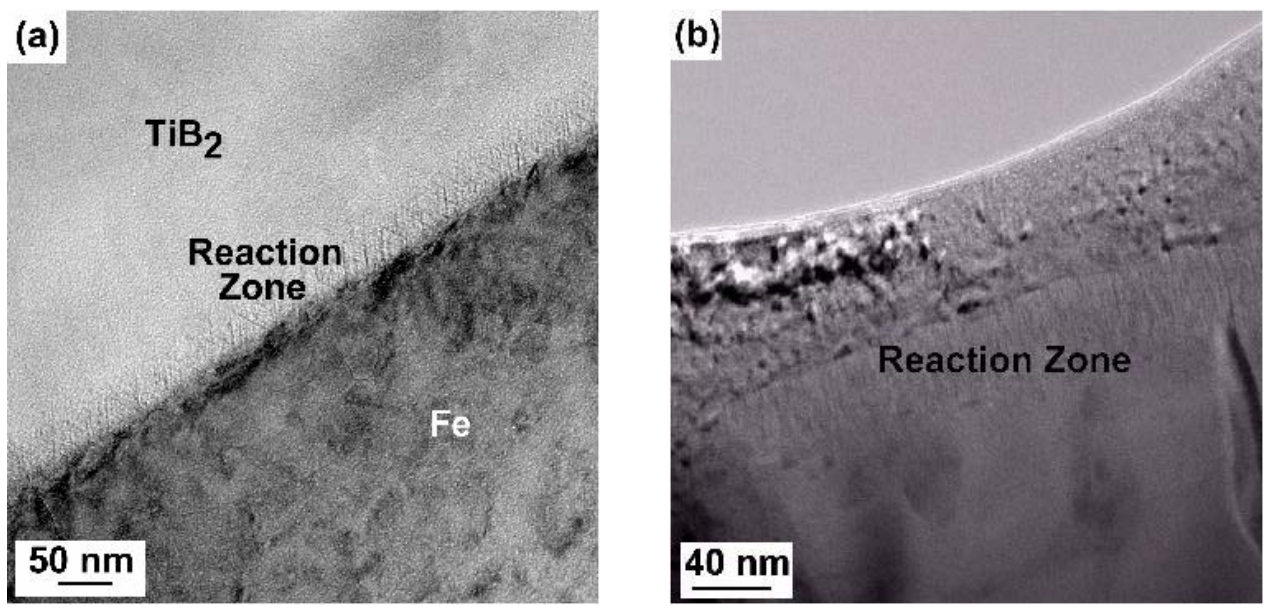

Fig. 4.8. High-resolution TEM images showing a nanosized reaction zone between the $\mathrm{TiB}_{2}$ particle and iron.

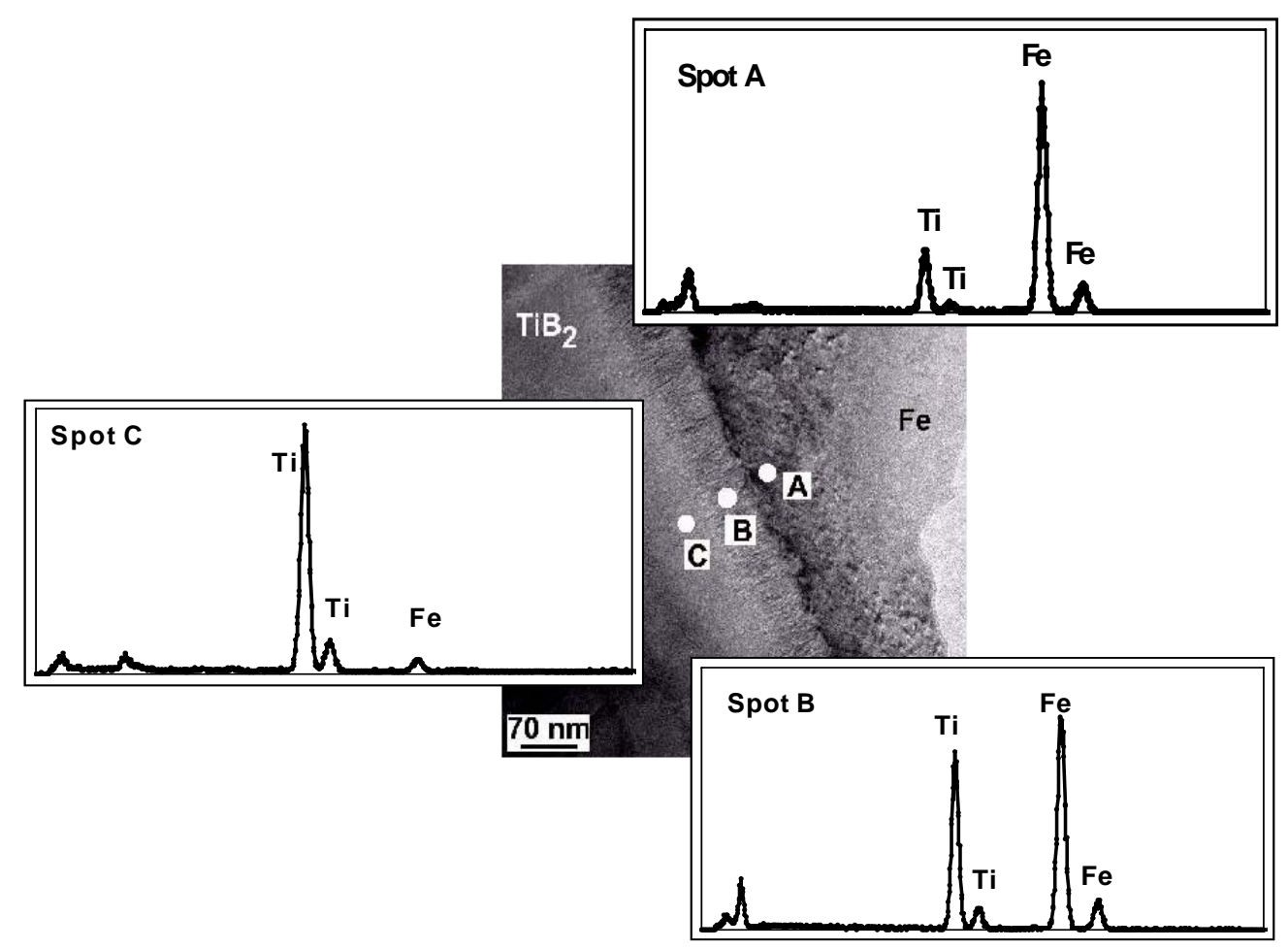

Fig. 4.9. TEM image showing a reaction zone between the $\mathrm{TiB}_{2}$ particle and the corresponding EDS spectra.

analysis indicate that the coatings are sound and that the process has the potential to produce a variety of ceramic coatings on different metallic substrates.

As with the IR lamp coating efforts, the focus in this work was on processing Fe-Al-based coatings using lasers. Our intention was to identify Fe-Al as a suitable binder (matrix) system for $\mathrm{TiB}_{2}$ to deposit $\mathrm{TiB}_{2} / \mathrm{Fe}-\mathrm{Al}$ composite coating on ferrous and nonferrous (aluminum-alloy) substrates with better process control and repeatability. Therefore, it was considered essential to first succeed with a laser-based Fe-Al coating alone, before attempting a $\mathrm{TiB}_{2} / \mathrm{Fe}-\mathrm{Al}$ composite coating on ferrous and nonferrous substrates. Accordingly, the major focus in the laser-based tests was on Fe-Al coatings. 
Figure 4.10 shows typical cross-sectional optical microscopy images of the samples coated with a $25 \mathrm{~mol} \% \mathrm{FeAl} / 75 \mathrm{~mol} \% \mathrm{Al}$ mixture using the laser-based processing technique with the processing parameters noted in Sect. 4.3.1: laser power settings of $1250 \mathrm{~W}$ (low), $1500 \mathrm{~W}$ (medium), and $1750 \mathrm{~W}$ (high), and travel speed kept constant at $220 \mathrm{~cm} / \mathrm{min}$. Note that these micrographs show a near-surface band that was not etched by the 2 vol \% Nital solution. The size of this band increases with an increase in the power, as is observable from the images in Fig. 4.10. Furthermore, as can be seen, the integrity of this layer is excellent, and the interface between this layer and the heat-affected zone in the substrate is free of cracks and voids.

Figure 4.11 shows the iron and aluminum concentrations (obtained using EPMA) as functions of position. As is clear from the graph, power input has a significant influence on the maximum concentration of aluminum at the surface and its distribution as a function of depth. A maximum aluminum content of about 31 at. \% is obtained at the surface for the lowest power input but drops to about 15.0 at. \% at increased power levels. X-ray diffraction shows the presence of an iron aluminide in the sample, with the highest aluminum content at the surface and its absence when the aluminum content decreases to lower values. This is consistent with the known phase equilibria information, which shows that the solid solubility of aluminum in iron is $\sim 18-20.0$ at. $\%$ at $200^{\circ} \mathrm{C}$ [42-43]. Furthermore, the depth to which

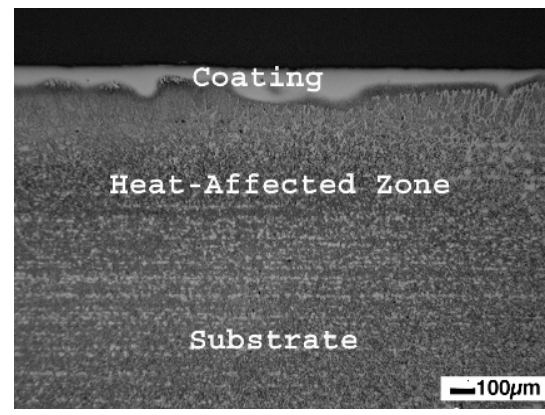

(a)

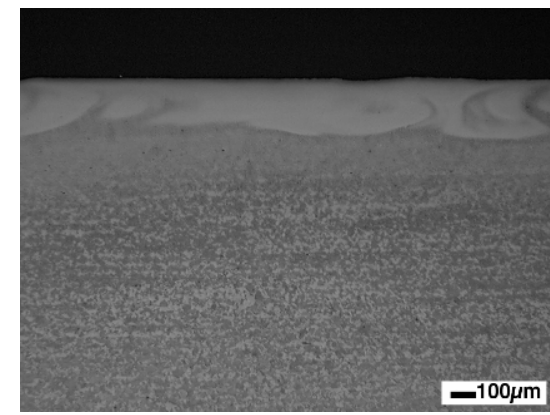

(b)

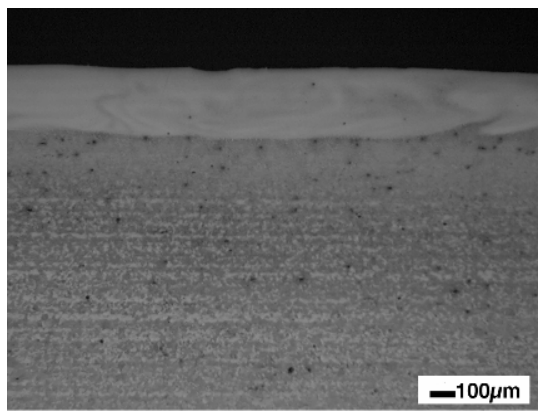

(c)

Fig. 4.10. Cross-sectional optical micrographs of samples with Fe-Al alloy coatings prepared using $75 \mathrm{~mol} \% \mathrm{Al}$ precursor coating and a laser power of (a) 1250 W, (b) 1500 W, and (c) 1750 W. Samples were etched with 2 vol \% Nital solution.

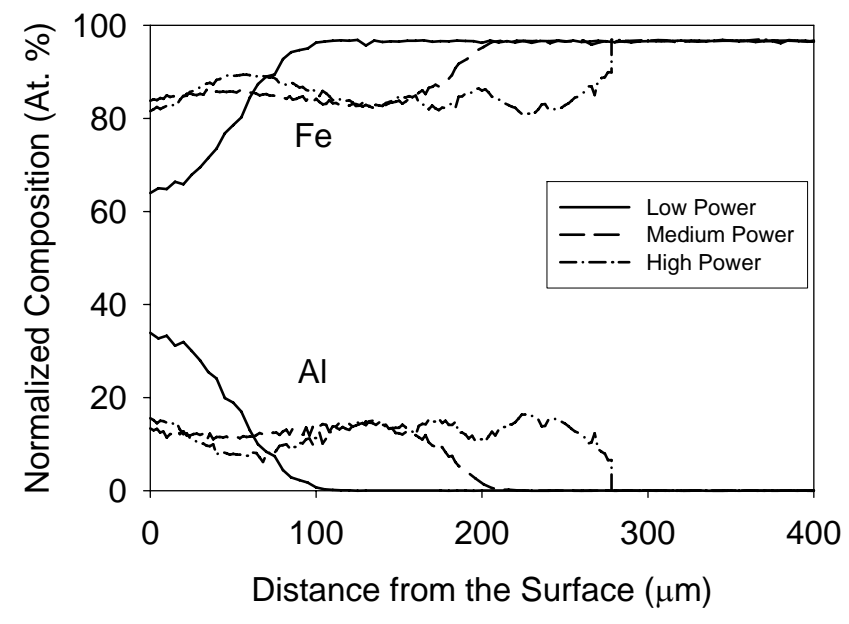

Fig. 4.11. Variation in iron and aluminum concentrations within the near-surface region as a function of laser power, obtained using EPMA. Fe-Al coatings prepared using the $75 \mathrm{~mol} \% \mathrm{Al}$ precursor coatings were used for these measurements. 
aluminum is detected increases with increasing power input. At the lowest power input, aluminum can be detected to a depth of $\sim 100 \mu \mathrm{m}$ from the surface, while at the highest power input, it is observed up to about $275 \mu \mathrm{m}$. This clearly shows that intermixing, interdiffusion, and dilution increase with increasing power inputs. A comparison of Figs. 4.9 and 4.10 shows that the size of the unetched and lightly etched regions is comparable to the distance to which there is detectable aluminum concentration.

Careful comparison of the aluminum concentration as a function of position for the different power inputs shows an additional trend. As the power input increases from low to medium, the maximum aluminum content at the surface decreases by about $45 \%$ while the depth to which aluminum is present increases by about $100 \%$. However, as the power increases from medium to high levels, the maximum concentration of aluminum at the surface remains approximately the same, yet aluminum is observable to a depth that is about 1.5 times greater than that observed at medium power levels. This would tend to indicate that more aluminum is retained within the sample at higher power levels.

Figure 4.12 shows the variation in Knoop hardness values as a function of position within the coating, the heat-affected zone, and the substrate. Indentations were made at an inclination to the normal to the surface $\left(\sim 20^{\circ}\right)$ in order to maximize the number of readings that could be obtained within the coating. It can be seen that the hardness values within the coating are much larger (Knoop hardness values $>400$ ) than those obtained for the base material (Knoop hardness values $<300$ ). It is intriguing to note that the coating prepared with the lower aluminum content in the sprayed layer [Fig. 4.12(a)] exhibits, on average, larger hardness values in the surface layers than does the coating with the higher aluminum content precursor layer [Fig. 4.12(b)]. Higher peak hardness values were also observed in this sample with the lower aluminum content, as shown in Fig. 4.12(a).

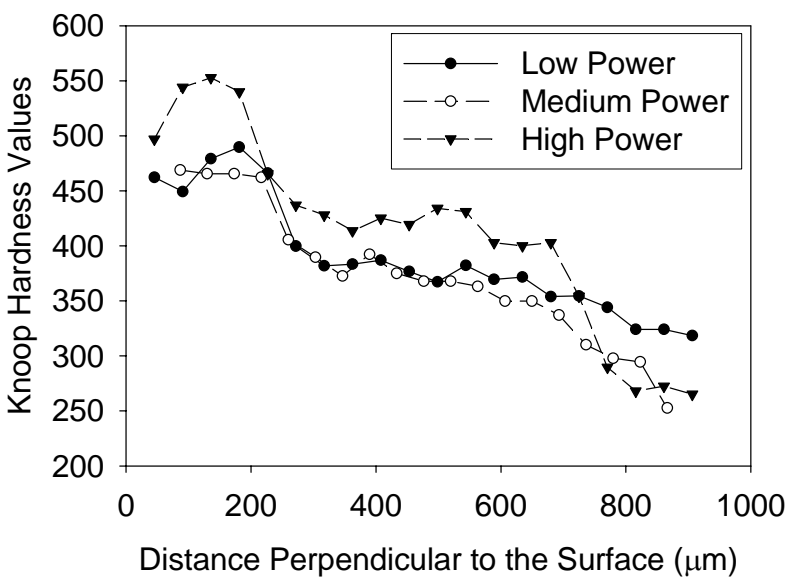

(a)

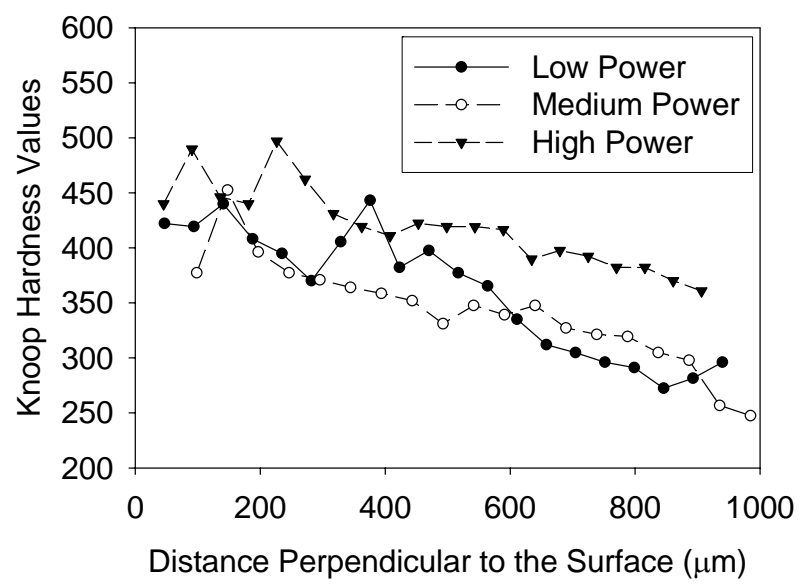

(b)

Fig. 4.12. Variations in Knoop hardness values with laser power as a function of distance perpendicular to the surface in coatings prepared with (a) precursor layer with $43.5 \mathrm{~mol} \% \mathrm{Al}$, and (b) precursor layer with $75 \mathrm{~mol} \%$ Al.

Figure 4.13(a) shows the results obtained from the block-on-disk wear tests. The cumulative weight loss obtained over a period of 10 min has been normalized with that obtained for the base material. A study of the wear rates shows that processing conditions and the composition of the initial coating layer both have a significant effect on the wear properties. The effect of the laser power can be observed by comparing the properties of the samples with those of the group that had the same initial composition of the sprayed coating. Note that the wear property is best at low laser power and worsens with increasing laser power. 


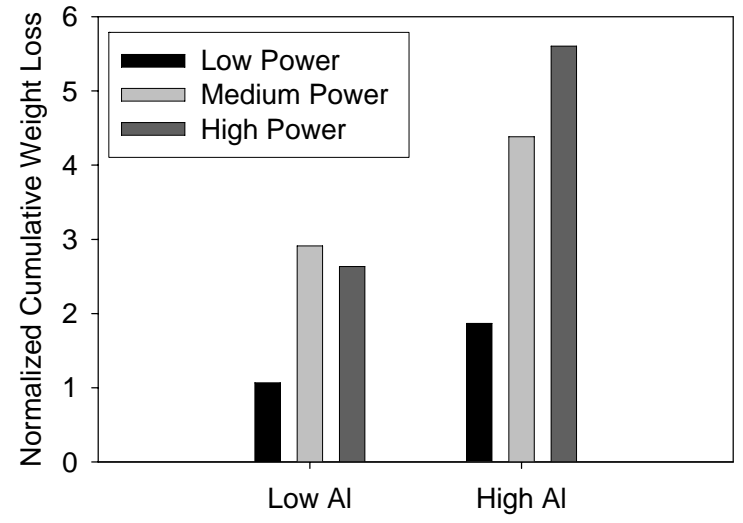

(a)

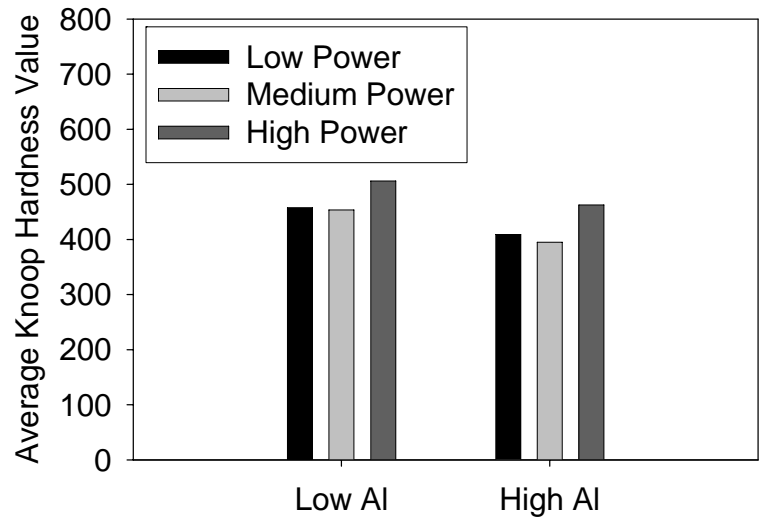

(b)

Fig. 4.13. Variation in (a) normalized cumulative weight loss and (b) average Knoop hardness value over a 275- $\mu \mathrm{m}$-thick region at the surface as a function of precursor aluminum content and laser power.

Some interesting trends can be seen in the relationship between the wear properties shown in Fig. 4.13(a) and the average Knoop hardness values within the region $275 \mu \mathrm{m}$ from the surface shown in Fig. 4.13(b). The most prominent feature is that the average wear in the coatings prepared with the higher-aluminumcontent precursor layer is inferior to that in coatings with the lower-aluminum-content precursor layer. This is consistent with the trends in the average hardness values, as shown in Fig. 4.13(b). For the same power levels, the average hardness in the samples prepared with the higher-aluminum-content precursor is lower, with correspondingly larger wear rates.

The trends in the wear properties can be related to the microstructure of the coatings. As can be observed from Fig. 4.11 and as argued earlier, there was evidence for the formation of iron aluminides on the surface only when the samples were processed with low laser power. In the samples processed with the higher laser power, dilution resulted in the formation of a Fe-Al solid solution rather the iron aluminides. The effect of this microstructural change is dramatically reflected in the degradation of the wear properties. For example, if we consider the coatings prepared with the precursor containing $43.5 \%$ aluminum (low aluminum), the change in wear properties between the low and medium power settings is drastic (about a factor of 3 ) while the average hardness decrease is only about $5 \%$. The change in power setting from medium to high results in an increase in the average hardness of about $10 \%$, which improves the wear properties by a comparable magnitude. These results, which show a significant influence of the phase constituents of the coating on wear behavior, are consistent with previous measurements conducted on the wear properties of bulk aluminides and Fe-Al solid solutions. These studies [44-46] showed that the wear properties of the aluminides were much better than those of the solid solution. Our observations showing the wear properties of Fe-Al coatings are comparable to those of 4340 steel merit further study. Previous work on bulk materials shows that the wear properties of the iron aluminides are a strong function of the composition. For example, $\mathrm{Fe}_{3} \mathrm{Al}$ with a composition of $\mathrm{Fe}_{75} \mathrm{Al}_{25}$ was found to be worse than 4340 in its wear properties, while $\mathrm{Fe}_{3} \mathrm{Al}$ with a nominal composition of $\mathrm{Fe}_{66} \mathrm{Al}_{34}$ was found to be better than 4340 with respect to wear properties. On the other hand, FeAl with a nominal composition of $\mathrm{Fe}_{64} \mathrm{Al}_{36}$ showed wear properties comparable to that of 4340 steel. Alloying additions of $\mathrm{Cr}$ and $\mathrm{Ti}$ to FeAl was shown to improve the wear properties [47-52].

Although in general Fe-Al coatings are synthesized on a steel substrate, it was noticed via XRD analysis that such coatings contain variations in stoichiometry of the composition. This is due to the effect of processing conditions on intermixing, interdiffusion, and the dilution of components of the coating precursor (iron and aluminum). The coating has the highest aluminum content at the surface; the aluminum content decreases to background levels, depending upon the aluminum content in the precursor used to synthesize the coating as well as the processing conditions. For example, in earlier trials, a 
maximum aluminum content of $\sim 31$ at. \% was obtained at the surface for the lowest laser power input $(1250 \mathrm{~W})$ and dropped to $\sim 15.0$ at. \% for increased power levels $(>1500 \mathrm{~W})$ for $75 \mathrm{~mol} \% \mathrm{Al}$ in the precursor.

Such variations in the stoichiometry of Fe-Al are expected to greatly influence both the mechanical and the corrosion/oxidation properties of the coatings. Thus, it was considered very important to study the relationship between the microstructure and the stoichiometry of these Fe-Al coatings to further establish their relationship with mechanical (wear/erosion) and chemical (corrosion/oxidation) properties in order to tailor the properties of the coatings.

\subsubsection{Oxidation Response of Coating}

The oxidation response of the samples was evaluated on the basis of both long-term and short-term exposures of coated samples. Identification of the type and/or nature or mechanism of the response, along with the kinetics of the oxidation, was part of the effort. Because the laser-processing method provided the best Fe-Al coatings, the oxidation studies were conducted on only these samples. These coupons were selected for oxidation from among many other sets of coupons processed with different materials and process parameters because initial XRD analysis indicated that these coupons provide a wide and distinct range of Fe-Al stoichiometry. The coupons were sectioned along the interface between the coating and the substrate on a slow-speed diamond laced wheel machine. This provided stress-free sections of the coating ( $\sim 500 \mu \mathrm{m}$ thick), which were further cut into smaller samples of $5 \times 5 \mathrm{~mm}$. Samples with similar dimensions were also cut out from the substrate material (4340 steel) for performance comparison.

\section{Long-Term Exposure Studies}

For long-term exposure these samples were exposed to air at a constant temperature of $600^{\circ} \mathrm{C}$ inside an electric resistance box furnace. Initially, it was decided that weight change measurements would be conducted at 120, 240, 480, 960, and $2464 \mathrm{~h}$. However, because of very slow oxidation kinetics (high oxidation resistance), weight changes are reported only for 120,504 , and $2464 \mathrm{~h}$. Weight change in relation to time of exposure for various laser processing powers is presented numerically in Table 4.3 and graphically in Fig. 4.14.

Table 4.3. Weight change as function of time during air oxidation of lasercoated 4340 steel coatings at $600^{\circ} \mathrm{C}$

\begin{tabular}{ccccc}
\hline \multirow{2}{*}{$\begin{array}{c}\text { Exposure time } \\
\text { (h) }\end{array}$} & $\begin{array}{c}\text { 4340 steel } \\
\text { substrate }\end{array}$ & $\begin{array}{c}\text { 1200 W } \\
\text { power }\end{array}$ & $\begin{array}{c}\text { 1500 W } \\
\text { power }\end{array}$ & $\begin{array}{c}\text { 1750 W } \\
\text { power }\end{array}$ \\
\hline 0 & 302.10 & 779.40 & 452.21 & 496.50 \\
120 & 303.17 & 781.03 & 453.17 & 498.70 \\
\hline$\%$ wt. gain & 0.3542 & 0.2091 & 0.2367 & 0.4431 \\
0 & 546.20 & 770.00 & 335.80 & 513.40 \\
540 & 555.00 & 776.56 & 338.50 & 517.94 \\
\hline$\%$ wt. gain & 1.6111 & 0.8519 & 0.8040 & 0.8843 \\
\hline 2764 & 200.90 & 618.20 & 331.90 & 750.20 \\
$\%$ wt. gain & 230.07 & 646.70 & 356.33 & 798.10 \\
\hline
\end{tabular}




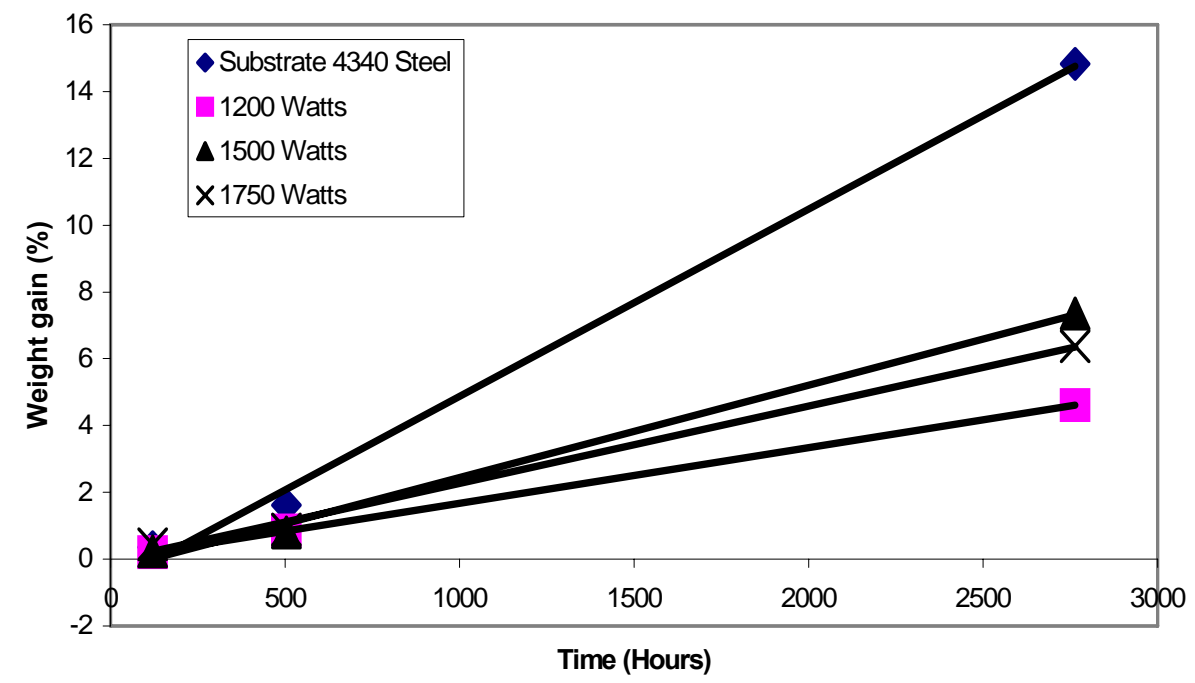

Fig. 4.14. Relationship between percentage of weight change and time of exposure for oxidized samples.

As can be seen in Fig. 4.14, the regression analysis of the experimental data provided a linear fit for weight change and time of exposure (oxidation) behavior in all coatings and the substrate sample. Such behavior is represented by the following equation:

$$
W=K t+C,
$$

where $W$ is percentage weight gain, $t$ is oxidation time (exposure time), and $K$ and $C$ represent oxidation kinetic constants. Table 4.4 lists all the values of $K$ and $C$ for these samples.

Although for the initial period (up to $170 \mathrm{~h}$ ) the percentage weight gain for the 4340 steel substrate is slightly lower than the percentage weight gain for samples processed at $1750 \mathrm{~W}$, it is significantly higher $(>1.5 \times)$ than all coated samples for rest of the range of exposure time, as is evident in Fig. 4.14. Among coated samples, the percentage weight gain for the sample processed at $1750 \mathrm{~W}$ is higher than those in samples processed at 1200 and $1500 \mathrm{~W}$. It appears that both samples processed at 1200 and $1500 \mathrm{~W}$ had similar percentages of weight gain without much variation throughout the exposure time. Similarly, the lower values for the oxidation rate constant $K$ (Table 4.4) for all coated samples as compared to substrate samples $(<0.5 \times)$ is due to substantial improvement in the oxidation resistance of the coated samples. It is also indicative of the significantly slower kinetics of oxidation in all coated samples as compared with that of the substrate sample. Furthermore, among coated samples, the oxidation rate constant $K$ increases as the laser power used to process the sample increases. A significant influence of the phase constituents of the coating on oxidation behavior is consistent with previous measurements conducted on the oxidation and wear properties of bulk aluminides and Fe-Al solid solutions, which showed that the oxidation and wear properties of the aluminides were much better than those of the solid solution.

Table 4.4. Oxidation kinetic constants for coatings and substrate at constant temperature $\left(600^{\circ} \mathrm{C}\right)$

\begin{tabular}{lcc}
\hline \multicolumn{1}{c}{$\begin{array}{c}\text { Processing power } \\
(\mathbf{W})\end{array}$} & $\begin{array}{c}\mathbf{K} \\
\left(\% \mathbf{~ h}^{-\mathbf{1}}\right)\end{array}$ & $\begin{array}{c}\mathbf{C} \\
\mathbf{( \% )}\end{array}$ \\
\hline 1200 & $16.89 \times 10^{-4}$ & -1.5993 \\
1500 & $29.48 \times 10^{-4}$ & -0.0606 \\
1750 & $24.73 \times 10^{-4}$ & -0.7818 \\
Baseline: 4340 steel substrate & $59.45 \times 10^{-4}$ & -0.4513 \\
\hline
\end{tabular}


Data in Table 4.4 and Fig. 4.14 clearly show the oxidation behavior of the coatings in comparison with that of the substrate. Even after the long exposure time of $2764 \mathrm{~h}$, all samples including the substrate indicated a linear oxidation rate at the constant exposure temperature $\left(600^{\circ} \mathrm{C}\right)$. Although such linear oxidation behavior is an indication of an ongoing oxidation process, it is clear that oxidation rate of the substrate is much higher (percentage weight gain $>2 \times$ higher) than that of the coated samples. The weight change in the coated samples, however, represented a very small spread in value (4-7\%) after $2764 \mathrm{~h}$ of exposure. These observations are indicative of increased oxidation resistance in the coated samples. It is possible that they would reach saturation oxidation behavior (indicated by a very low weight change) with further $(>2764 \mathrm{~h})$ exposure time.

The coated samples and the uncoated substrate continued to display similar general oxidation behavior for the long-duration exposure $(2764 \mathrm{~h})$ compared to the behavior observed initially for shorter exposure time $(540 \mathrm{~h})$. However, in contrast to the earlier findings for short-duration exposure $(540 \mathrm{~h})$, during the longduration exposure $(2764 \mathrm{~h})$ for coated samples, the sample processed at $1200 \mathrm{~W}$ showed the lowest percentage weight gain, and both samples processed at 1500 and $1750 \mathrm{~W}$ had similar percentage weight gains $(6-7 \%)$ with little variation throughout the exposure time. Similarly, the continued lower values for the oxidation rate constant $K$ during the 2764-h exposure time for all coated samples as compared with the values for the substrate samples (Table 4.4) are due to substantial improvement in the oxidation resistance of the coated samples. These values are also indicative of the fact that the kinetics of oxidation in all coated samples is significantly slower $(<40 \%)$ than in the substrate sample.

A distinctly higher oxidation resistance among Fe-Al coated samples compared to uncoated 4340 steel is due to presence of aluminum in the composition and stoichiometry of the Fe-Al coating. The degree of oxidation resistance (as measured by the percentage weight gain and the oxidation rate constant) appears to depend upon the content of aluminum in the Fe-Al coating composition. In the samples processed with the higher laser power, dilution resulted in the formation of Fe-Al solid solution rather iron aluminides and therefore reduced oxidation resistance. XRD analysis showed that the coating contains variations in stoichiometry of the composition (Figs. 4.15-4.17). These analyses indicated the presence of such phases

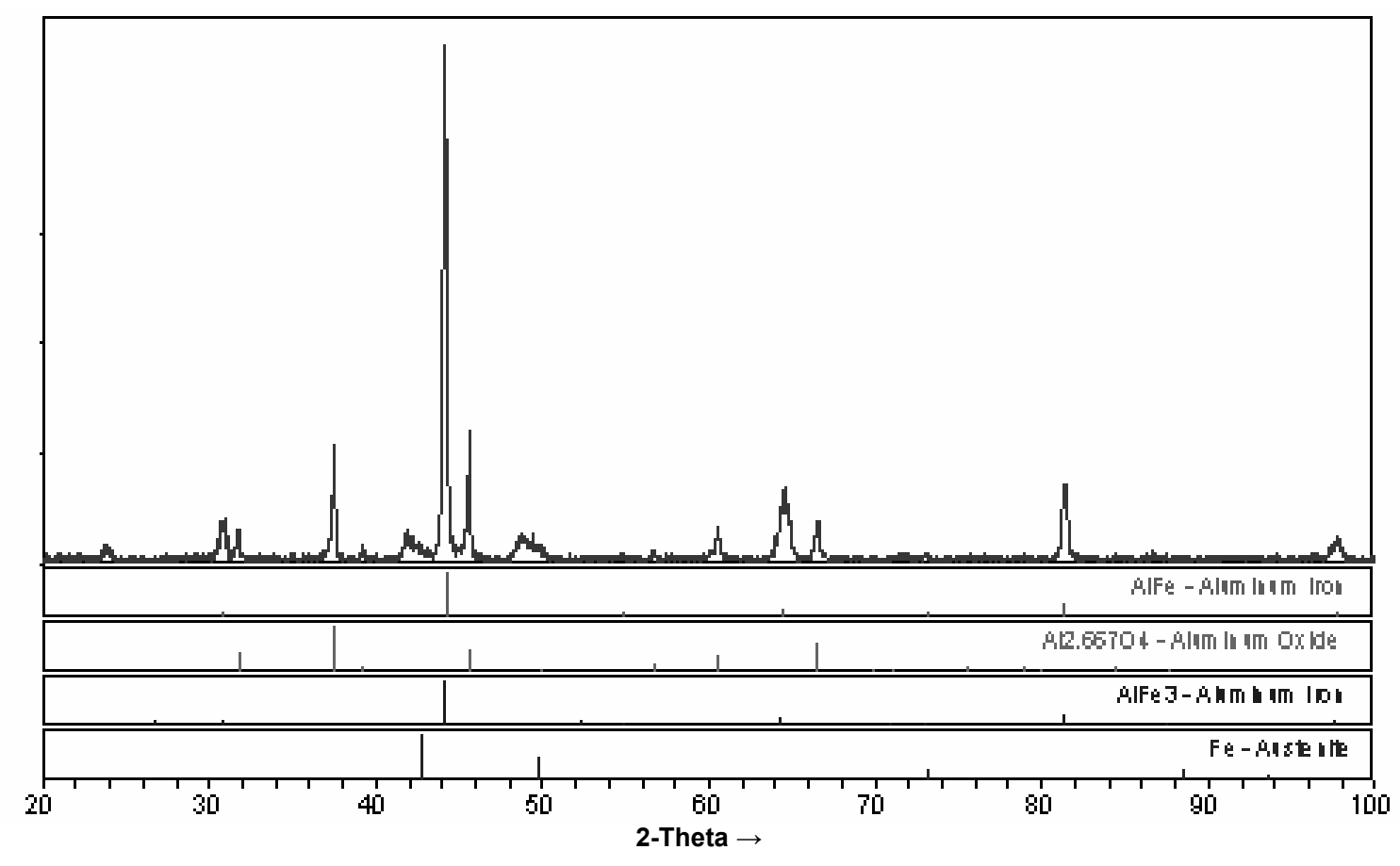

Fig. 4.15. X-ray diffraction (XRD) patterns obtained from Fe-Al alloy coatings prepared using $75 \mathrm{~mol} \%$ Al precursor and a laser power of $1250 \mathrm{~W}$. For clarity only peak positions of selected phases are shown in the figure. 


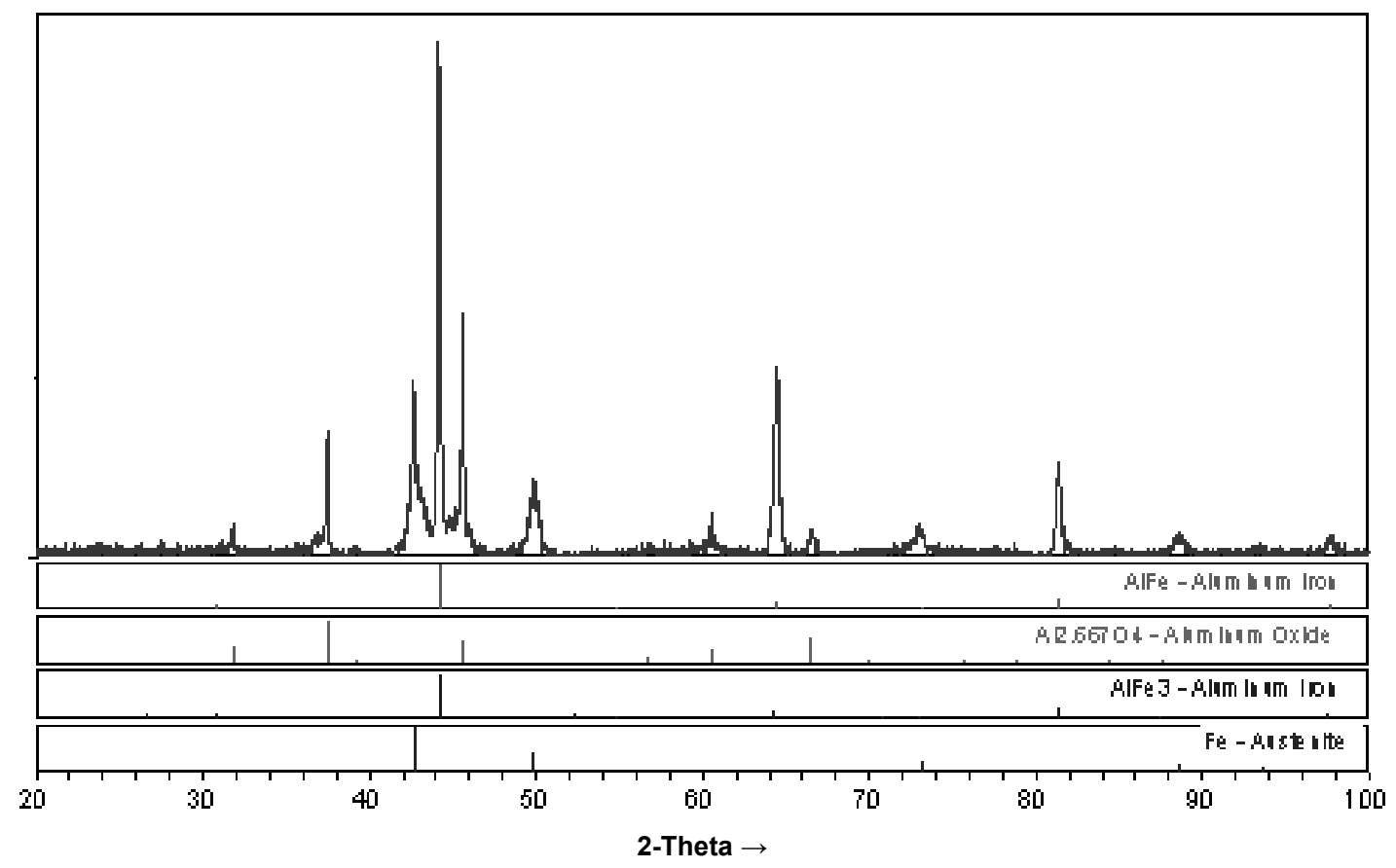

Fig. 4.16. XRD patterns obtained from Fe-Al alloy coatings prepared using $75 \mathrm{~mol} \% \mathrm{Al}$ precursor and a laser power of $1500 \mathrm{~W}$. For clarity only peak positions of selected phases are shown in the figure.

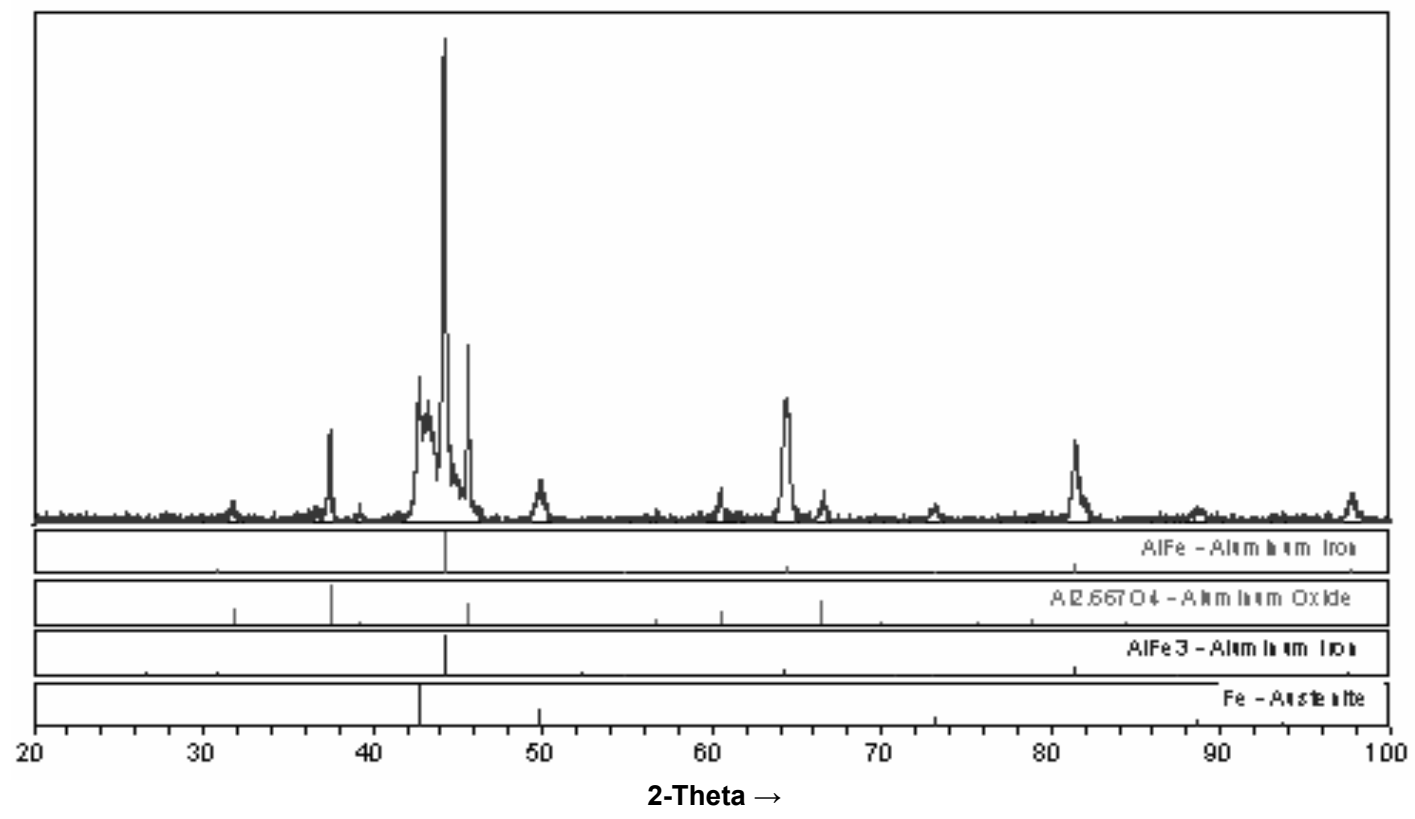

Fig. 4.17. XRD patterns obtained from Fe-Al alloy coatings prepared using $75 \mathrm{~mol} \% \mathrm{Al}$ precursor and a laser power of $1750 \mathrm{~W}$. For clarity only peak positions of selected phases are shown in the figure. 
as $\mathrm{AlFe}$ and $\mathrm{AlFe}_{3}$ (which can be observed in equilibrium phase diagram for Fe-Al shown in Fig. 4.18) as well as aluminum oxide, and support the fact that aluminum exists in various stoichiometries.

Because laser processing is a near nonequilibrium process, it tends to produce many unconventional phases that often are not referenced in the standard database. This may be the reason that although the data show many additional peaks that could be related to aluminum-base phases, these phases remain unidentifiable (Figs. 4.15-4.17). But an in-depth analysis of the various phase fields, the stability of phases, and the effect of compositional variations could act as a guideline that could be extended to nonequilibrium conditions under certain assumptions. We used the Scheil module of the ThermoCal ${ }^{\mathrm{TM}}$ software for computational calculations to predict the sequence of phase evolution from the liquid phase of Fe-Al (the coating precursor composition). This module is based on the Scheil Gulliver model [53-54], which assumes that there is fast diffusion in the liquid phase and no diffusion in the solid phase. These assumptions can be extended to laser processing conditions. As during solidification of the melt pool, the rapid rate of the process does not allow any diffusion in the solid phase during processing.

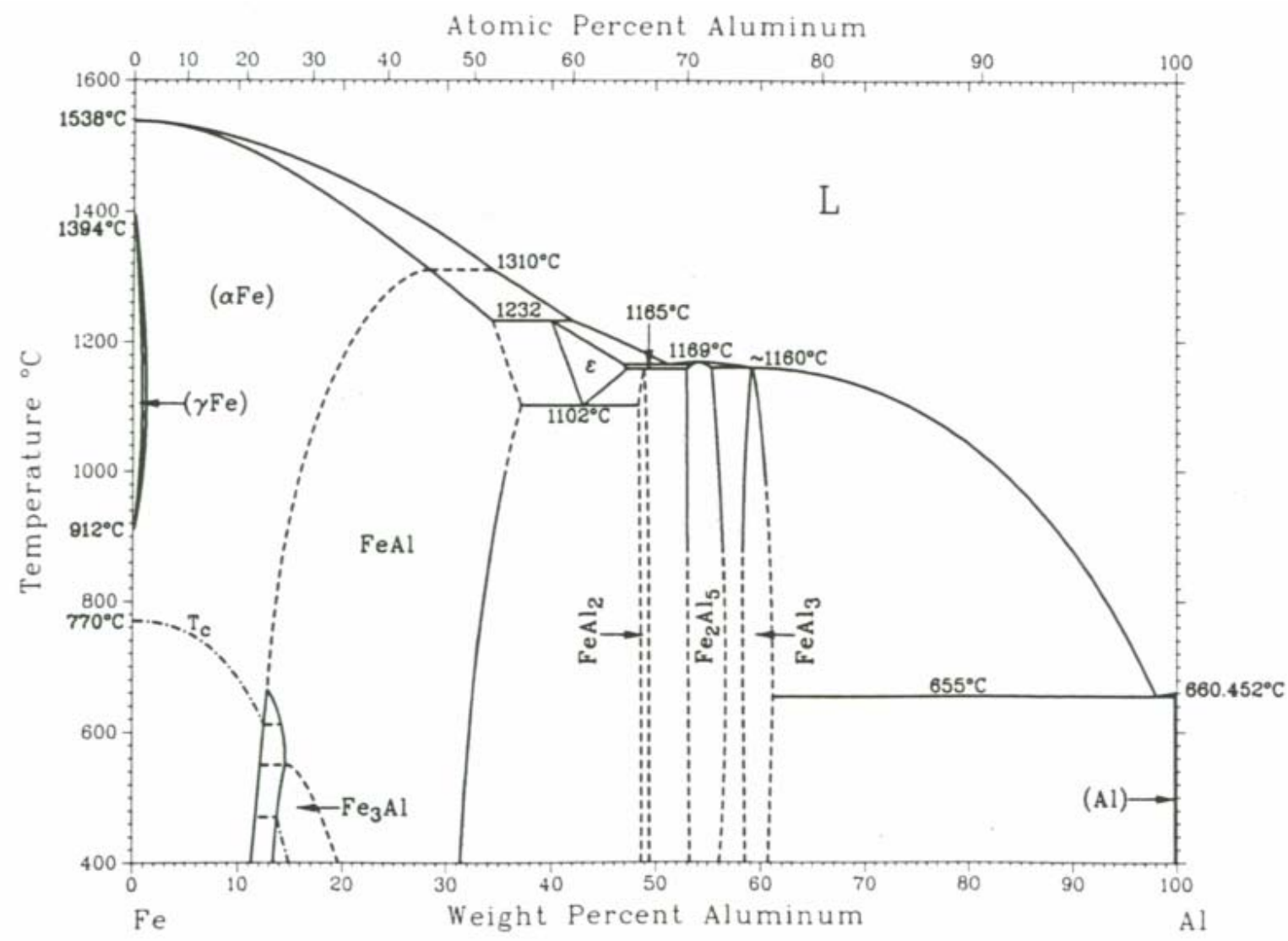

Fig. 4.18. Phase diagram for Al-Fe system.

Calculations were started from a temperature of $1500 \mathrm{~K}$ (approx $50^{\circ}$ higher than the temperature at which only the liquid phase exists), and the temperature was lowered in $1 \mathrm{~K}$ steps. The calculation was repeated till no liquid was left. The results of the analysis are shown in Fig. 4.19. The first phase to precipitate from the liquid is the body-centered cubic (bcc) phase $(\alpha-\mathrm{Fe})$. Further cooling indicated that the sequence of phase appearance was $\alpha$-Fe (bcc) followed by FeAl (a complex-defect hexagonal structure) and $\gamma$-Fe in the subsequent stages. The calculated terminal solidification temperature was $835 \mathrm{~K}$, at which point the 


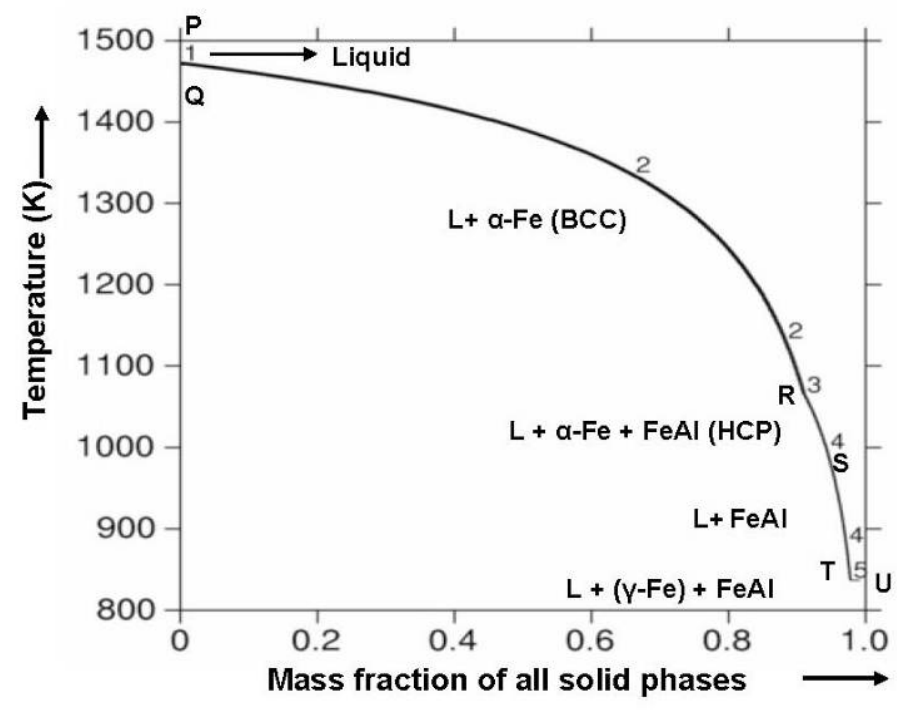

Fig. 4.19. Solidification path traced using calculations based on Scheil assumptions.

mole fraction of the solid phases is equal to 1 . Hence, the solidification path can be summarized as follows:

$$
\begin{aligned}
\text { Liquid } \rightarrow \text { Liquid }+\alpha-\mathrm{Fe}(\mathrm{BCC}) & \rightarrow \text { Liquid }+\alpha-\mathrm{Fe}(\mathrm{BCC})+\mathrm{FeAl}(\mathrm{HCP}) \\
& \rightarrow \text { Liquid }+\mathrm{FeAl} \rightarrow \text { Liquid }+(\gamma-\mathrm{Fe})+\mathrm{FeAl}
\end{aligned}
$$

These computational evaluations indicate that the dominant phase in the solidified coating should be FeAl along with austenitic iron. This also supported by XRD analysis (Figs. 4.15-4.17). Both phases are known to possess higher oxidation resistance. Although XRD (experimental) and Scheil (computational) analyses together reasonably well identify and verify the evolution of phases in the coating, the presence of additional phases in minor numbers and quantities may be due to the level of temperature and the cooling rate generated at different laser-processing powers. Once we can reliably identify phases in the coatings under current laser-processing conditions and correlate these phases with wear and oxidation properties, we can use computational techniques to design phase formation and select laser-processing conditions to tailor coatings with the wear and oxidation properties appropriate for various field applications.

\section{Short-Term Exposure Studies}

The short-duration, accelerated exposure studies on laser-coated Fe-Al samples used the TGA technique. TGA allowed a study of the oxidation response of the samples at multiple temperatures. Thermogravimetry, as the name indicates, is measurement of weight gain as a function of temperature or time at constant temperature. As the temperature or time (at a constant elevated temperature) increases, the metal is oxidized and in the process gains weight. The rate of weight gain as a function of time would reveal how quickly or how slowly the material is oxidized and thus helps in deducing the oxidation kinetics of the material.

The base 4340 steel forms an iron oxide layer. However, the iron oxide layer possesses numerous defects, and therefore, the oxidation continues. The mass diffusion of oxygen and/or metal ions through this porous layer is the only limiting factor. Coating and surface engineering can change this scenario and improve the oxidation resistance of the material. In case of coating it is desirable that once a layer of appreciable thickness has been formed in an oxidizing atmosphere, that layer remains intact. In addition, 
the layer should be self-healing and nonporous. The coating will prevent further oxidation because lattice diffusion of oxidizing species and/or metallic species is usually very slow and rate-limiting.

The weight gain due to oxidation under a constant temperature as a function of time reveals the mechanism of oxidation and/or rate-limiting. A parabolic rate of change is best, because once an oxidation layer is formed, this change rate will slow down further oxidation. The rate of the oxidation reaction is therefore inversely proportional to the scale thickness or the weight of oxide formed.

One of the primary goals of this project was to produce a coating that is a significant improvement over the base substrate. Even though the $\mathrm{Cr}, \mathrm{Ni}$, and Mo present in 4340 steel make this steel more resistant to oxidation than is plain carbon steel, the amount of oxidation is still significant. Therefore, TGA studies were undertaken for the coating and the substrate. The coating on the substrate cannot be directly heated in a furnace, as the weight gain due to oxidation of the substrate would shadow the coating. Hence, the substrates were carefully machined from the coating, giving a thin layer of about $100 \mu \mathrm{m}$. The resulting samples were essentially the composite microstructure formed in laser processing. It should be noted that even though the application temperature is about $450^{\circ} \mathrm{C}$, local variation, fatigue, and thermal stress subject the surface materials to more severe conditions. Also, the phase transformation of the steel at about $850^{\circ} \mathrm{C}$ can significantly affect the oxidation behavior. Therefore, temperatures up to $900^{\circ} \mathrm{C}$ were investigated.

While the samples were being heated (at $10^{\circ} \mathrm{C} / \mathrm{min}$ ), some oxidation occurred. However, the weight gain was not significant because the duration of heating was less than the holding time. The initial weights of the samples were different; hence, for effective comparison, the weight was normalized with respect to initial weights. Typical time-percentage weight gains (normalized) at $900^{\circ} \mathrm{C}$ for the substrate with the coating samples laser-processed at three different laser power settings are plotted in Fig. 4.20. These three samples are referred to as $1250-\mathrm{W}, 1500-\mathrm{W}$, and $1750-\mathrm{W}$ samples, respectively, in this section.

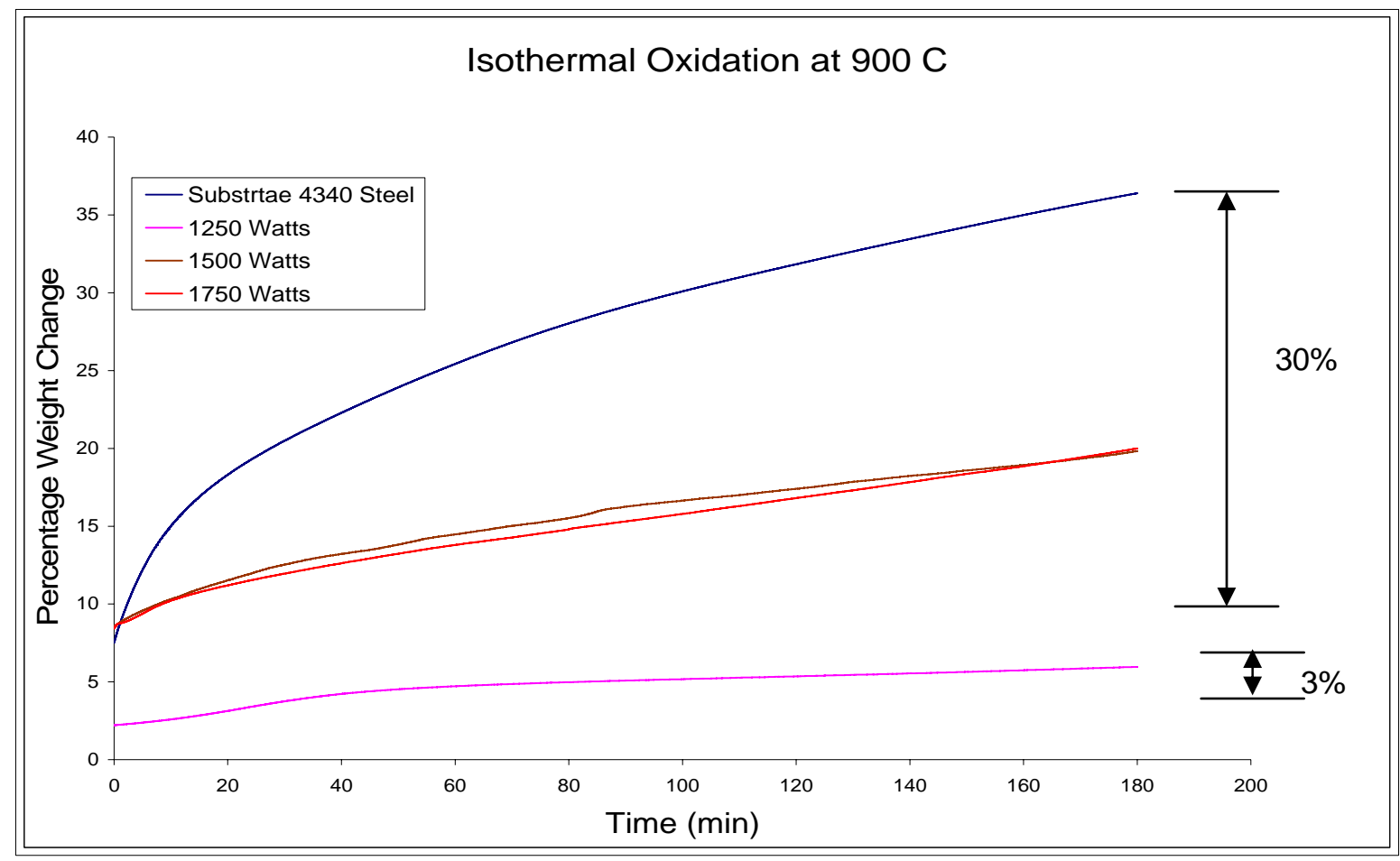

Fig. 4.20. Percentage weight change (normalized against initial weight) of the substrate and the laser processed samples. 
The curve-fitting with high correlation $\left(\mathrm{R}^{2}>0.98\right)$ indicates a power law relationship between the percentage weight gain and time during oxidation of the substrate and a cubic relationship during oxidation of the sample processed at a laser power of $1250 \mathrm{~W}$. Notice that the oxidized layer has the tendency to rapidly thicken in the initial stages followed by a slowdown in the thickening rate at later stages. The weight gain percentages varied over a wide range (30\% vs $3 \%)$ in the samples tested. It should also be noted that the initial weight gains are not zero. This is due to some oxidation taking place during heating (at a rate of $10^{\circ} \mathrm{C} / \mathrm{min}$ ) before the isothermal hold starts.

The approximate increase in the weight of the substrate was 30\%. By comparison, the weight gain observed for the 1250-W sample was approximately 3\%, which indicates the superior high-temperature oxidation resistance of the coating. Another key observation was that for the $1250-\mathrm{W}$ coating, the oxidation rate decreased with time (cubic behavior: polynomial 3). The curve became nearly horizontal, indicating that the initial buildup of the oxide layer prevents further oxidation. In contrast, there is a steady increase in the amount of oxidation over time for the substrate (power law).

It is clear from Fig. 4.20 and Table 4.5 that the 1250-W sample shows the best oxidation resistance. The behavior of the substrate at $900^{\circ} \mathrm{C}$ was best fitted with power-law. All other samples, the substrate, and the 1250-W sample at other temperatures exhibited polynomial of degree 2 . In all cases the correlation factor was greater than 0.98 . The isothermal oxidation weight gains for all the samples are reported in Table 4.5. The oxidation mechanism was further investigated by SEM. The presence of the oxide layer cause charging of the samples during electron microscopy. Hence, to prevent charging, the variable pressure mode (20 $\mathrm{Pa}$ air) was employed.

Table 4.5. Normalized percentage weight gain during isothermal oxidation of the substrate and the coatings

\begin{tabular}{|c|c|c|c|c|c|c|}
\hline \multirow{3}{*}{\begin{tabular}{|c|} 
Sample \\
Substrate 4340 steel
\end{tabular}} & \multicolumn{6}{|c|}{$\begin{array}{c}\% \text { Weight gain } \\
(\% \text { of weight at start of hold })^{a}\end{array}$} \\
\hline & \multicolumn{2}{|c|}{$500^{\circ} \mathrm{C}$} & \multicolumn{2}{|c|}{$700^{\circ} \mathrm{C}$} & \multicolumn{2}{|c|}{$900^{\circ} \mathrm{C}$} \\
\hline & $1.8(0.7)$ & Poly-2 & $4.8(1.6)$ & Poly-2 & $36.4(7.5)$ & Power law \\
\hline $1250 \mathrm{~W}$ & $1.2(1.4)$ & Poly-2 & $1.1(2.2)$ & Poly-2 & $6.0(2.2)$ & Poly-3 \\
\hline $1500 \mathrm{~W}$ & $\begin{array}{l}-1.2 \\
(11.5)^{b}\end{array}$ & Poly-2 & $1.9(9.7)$ & Poly-2 & $19.8(8.6)$ & Poly-2 \\
\hline $1750 \mathrm{~W}$ & $7.4(4.8)$ & Poly-2 & $27.6(11)$ & Poly-2 & $20(8.4)$ & Poly-2 \\
\hline
\end{tabular}

${ }^{a}$ Parenthetical values are normalized percentage weight gains at the start of isothermal holding (during heating).

${ }^{\boldsymbol{b}}$ Requires further investigation.

Figure 4.21(a) shows the substrate sample oxidized at $900^{\circ} \mathrm{C}$. The bright spots are oxide rich areas that may have been formed in a progressive nucleation-and-growth mode. For comparison, Fig. 4.21(b) shows the $1250-\mathrm{W}$ sample oxidized at $900^{\circ} \mathrm{C}$. Almost no oxidation is apparent on the surface of this sample.

Metal oxidation processes are used extensively in industry to protect materials against further corrosion and oxidation, and for the production of engineering ceramics and catalysts. The initial stages of oxidation (including oxygen adsorption and incorporation, oxide islands nucleation, and growth into a continuous film) have been actively studied and are now understood relatively well. These initial stages can be described, at least qualitatively, by the Wagner model of oxidation [55-56], in which diffusion across the oxide film is the rate-limiting process. The kinetic equations in this oxidation regime cannot be integrated exactly; only approximations for the oxide growth rate as a function of time can be obtained. This makes the experimental verification of theory based only on the measurements of the oxidation kinetics difficult. The oxidation rate provides information regarding the oxidation kinetics. The kinetics of the oxidation can be determined, at least qualitatively, from the time-weight gain relationship. For 

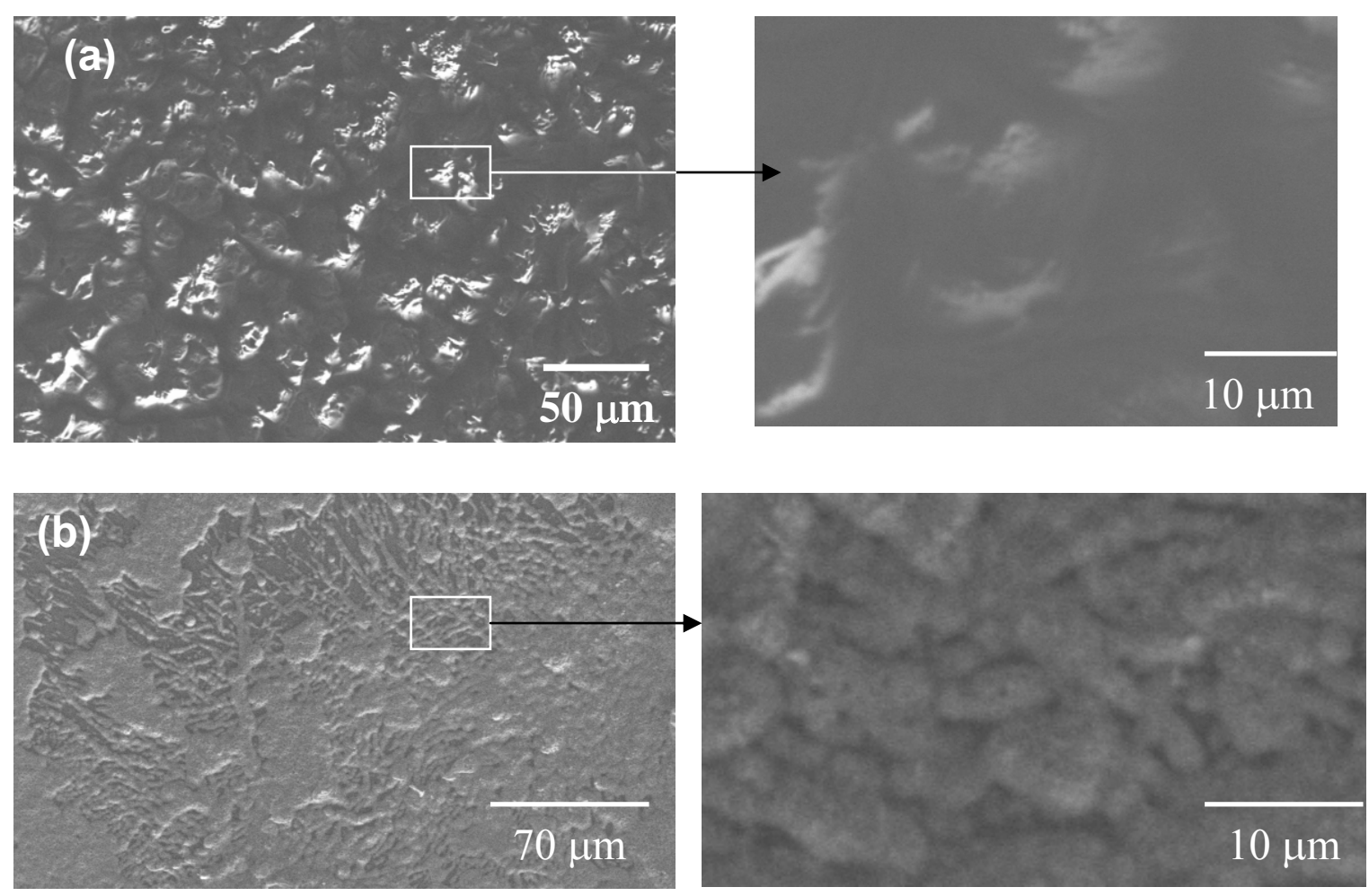

Fig. 4.21. Scanning electron micrograph of two samples oxidized in air at $900^{\circ} \mathrm{C}$ for $180 \mathrm{~min}$ : (a) 4340 steel sample; (b) 1250-W sample.

prolonged performance of the component, it is desirable that the surface layer, once formed, prevent further growth of the oxidized layer. Typically, this process is reflected by a parabolic or cubic relation.

On the other hand, if the oxidized layer is unable to prevent further oxidation (for example, if the coating is not adherent and/or cracks), the time-weight gain curve will follow a linear relation, indicating that oxidation is continuing. Eventually, the whole component will become oxidized, and the oxidation will cause failure. In such cases, mechanical failure or disintegration would be reflected by a sudden change in the slope of the weight-time curve.

It was found that the oxidation rate can be characterized as having a cubic relationship with time. The associated correlation factor $\left(\mathrm{R}^{2}\right)$ is very close to 1 , indicating excellent curve fitting. Deviation in the initial stage may be due to vaporization of the volatile phase, migration of mobile atoms, and/or formation of the very thin film. Changes in kinetics, if any, occur at an early stage, indicating good stability.

All the time-weight gain relationships were either cubic (the majority) or parabolic; none were linear. As noted above, a linear relationship is undesirable. Hence, it is good news that all the coatings' time-weight gain relationships are cubic. The oxidation trend depends on the dynamic condition around the sample and the volume and the shape (surface area) of the sample. Therefore, the oxidation responses observed for long-term exposure (shown in Fig. 4.14) differ from those observed for short-term exposure (Fig. 4.20). For short-term exposure, there is some degree of intrinsic oxidation resistance in the coating as well as in the substrate. It is likely that the substrate derives its oxidation resistance from the presence of nickel (which reduces oxidation potential) and chromium (which stabilizes the oxide layer formed initially). The oxidation resistance of the coating is due to the formation of a more tenacious, self-healing, adherent aluminum oxide layer in iron aluminides, which has much higher oxidation resistance. 


\subsubsection{Corrosion Response of Coatings}

The corrosion of metallic materials depends to a great extent on the formation of passive oxides. However, the formation of passive oxides may be influenced by several factors, such as the chemical composition of the material and processing parameters (mechanical as well as thermal and surface treatments). Steels have an iron oxide layer which is usually not passivated. However, iron-aluminide exhibits passivation due to an aluminum oxide film that is a few atomic layers thick, coherent, and tenacious. This alumina film in the aluminum-containing alloys is responsible for high-temperature oxidation resistance. In our laser-processed samples, the surface coating is a composite of several ironaluminide phases and a steel matrix. For passivation to occur, a monolithic coating of iron-aluminide is required, since the 4340 steel matrix (not passivated) would destroy any passivation. Monolithic coating is mechanically inferior owing to inadequate adherence and non-coherence.

The better corrosion resistance of laser-coated iron-aluminide than the base steel may be due to the superior oxide layer offered by mixed oxides against further corrosion. Even though the coating was not monolithic, the aluminide in the composite coating was responsible for reducing corrosion and oxidation. The variation in corrosion current and oxidation resistance clearly indicates the influence of laser parameters in improving the coating resistance. It is interesting to note that the same laser parameterpower-is responsible for providing the best resistance to both oxidation and corrosion, possibly originating from the best structure that provides protection via passivation.

Laser treatment is known to produce nonequilibrium surfaces and graded microstructures that are often reported to be useful for enhancing passive film properties and therefore the corrosion resistance of material. In the case of in situ synthesized aluminide coatings, however, the phases present and their stoichiometry are very important. The stoichiometry and formation of phases is a strong function of thermal dynamics during laser coating, as is reflected by our finding that the phase(s) and/or stoichiometry of the phase(s) formed at a laser power of $1200 \mathrm{~W}$ are most resistant to oxidation and corrosion.

Another source of corrosion is sulfidation, which is the reaction of a metal or an alloy with a sulfurcontaining species to produce a sulfur compound that forms on or beneath the surface on the metal or alloy. Sulfidation is one of the most severe modes of degradation of materials in applications for fossil combustion energy production. While iron-aluminide alloys possess good sulfidation resistance, little is known about their resistance to aqueous corrosion. An Fe-Al coating is expected to enhance resistance to corrosion originating from moisture as well as from various other gases containing sulfur and chloride ions.

The Tafel calculation [40-41] is used to estimate the corrosion current regularly present at the surface of a metal that is in contact with a corroding solution. Corrosion is expressed in loss of metal thickness per year. The thermodynamic $\alpha_{A}$ and $\alpha_{C}$ parameters of the Butler Volmer equation (below) are also determined.

$$
i=i_{o}\left[\exp \left(\frac{\alpha_{A} n F}{R T} \eta\right)-\exp -\left(\frac{\alpha_{C} n F}{R T} \eta\right)\right] \text {, }
$$

where

$i_{O}=$ exchange current density

$\eta=$ overpotential $\left(=E-E_{O}\right)$

$\eta=$ number of electrons

$\alpha_{A}=$ anodic transfer coefficient

$\alpha_{C}=$ cathodic transfer coefficient 
While the Butler-Volmer equation is valid over the full potential range, simpler approximate solutions can be obtained over more restricted ranges of potential. As overpotentials, either positive or negative, become larger than about $0.05 \mathrm{~V}$, the second or the first term of equation, respectively, becomes negligible. Hence, simple exponential relationships between current (i.e., rate) and overpotential are obtained, or the overpotential can be considered as logarithmically dependent on the current density. This theoretical result is in agreement with the experimental findings of the German physical chemist Julius Tafel [41], and the usual plots of overpotential vs log current density are known as Tafel lines. The slope of a Tafel plot reveals the value of the transfer coefficient for the given direction of the electrode reaction.

A voltametric curve $i=f\left(V_{g}\right)$ having a zero current potential can be processed according to the Tafel method. The Tafel method gives also access to other corrosion parameters such as the zero current potential (corrosion potential), the corrosion current, and the polarization resistance of the sample under study. The Tafel calculation is a complete tool to study the corrosion process at a metal surface. Therefore, in the current study corrosion of laser processed samples was carried out to obtain a Tafel calculation

Figure 4.22 illustrates the Tafel plots of laser Fe-Al coated 4340 steel including base material, and Table 4.6 summarize the corrosion current data in $\mathrm{H}_{2} \mathrm{SO}_{4}$ solution. Figure 4.23 shows the Tafel plots of similar specimens, and Table 4.7 presents the corrosion current data.

The Fe-Al coated samples exhibited significantly lower corrosion current $\left(\mathrm{I}_{\text {corr }}\right)$ in both sulfuric acid and sodium chloride solutions. The corrosion current roughly translates to corrosion rate. In other words, the laser-coated samples are significantly more resistant to corrosion than the base materials. Our corrosion experiments revealed that the coating synthesized with a laser power of $1500 \mathrm{~W}$ showed better resistance than the coatings processed at 1250 and $1750 \mathrm{~W}$ in both sulfuric acid and sodium chloride. Neither the coating nor the base 4340 steel exhibited a passivation tendency for the coating processed at 1250 and $1750 \mathrm{~W}$ in either medium. These observations are similar to the observations made during several studies on aqueous corrosion of bulk Fe-Al type intermetallic compounds [57-62].

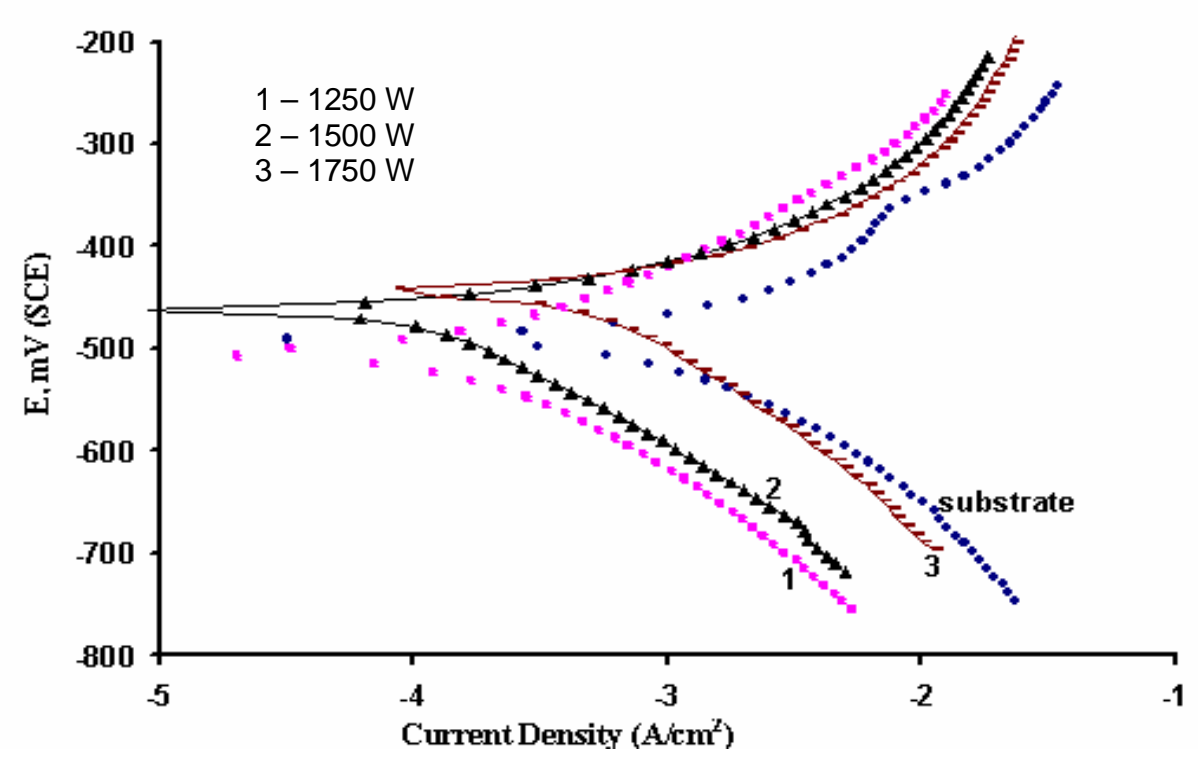

Fig. 4.22. Tafel plots in $1 N$ sulfuric acid solution. 
Table 4.6. Corrosion current in $1 \mathrm{~N} \mathrm{H}_{2} \mathrm{SO}_{4}$ solution

\begin{tabular}{lc}
\hline \multicolumn{1}{c}{ Sample } & $\begin{array}{c}\text { Corrosion current density } \\
\left(\mathbf{m A} / \mathbf{c m}^{2}\right)\end{array}$ \\
\hline Substrate & 2.2 \\
Coating 1 $(1250 \mathrm{~W})$ & 0.35 \\
Coating 2 $(1500 \mathrm{~W})$ & 0.19 \\
Coating 3 $(1750 \mathrm{~W})$ & 0.72 \\
\hline
\end{tabular}

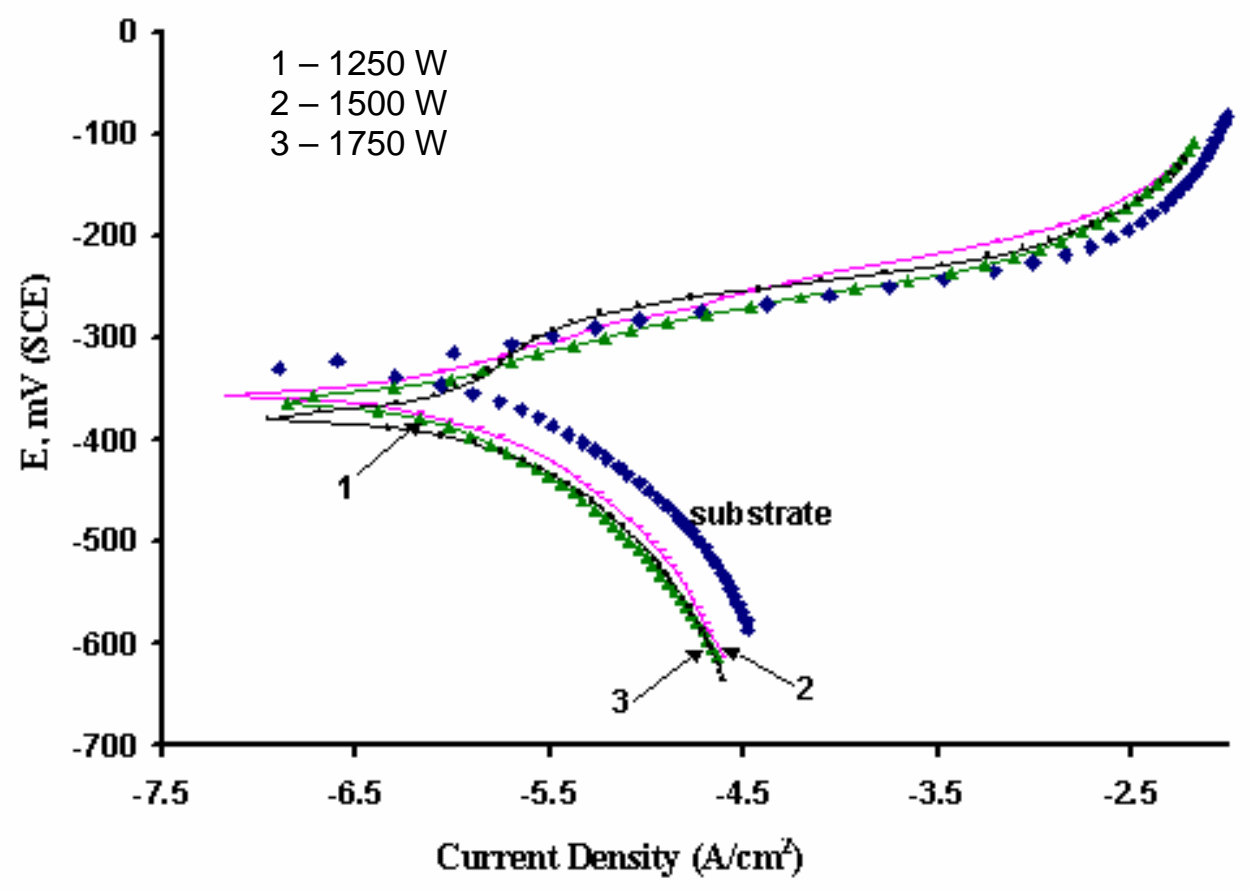

Fig. 4.23. Tafel plots in $1 \mathrm{~N}$ sulfuric acid solution.

Table 4.7. Corrosion current in $1 \% \mathrm{NaCl}$ solution

\begin{tabular}{lc}
\hline \multicolumn{1}{c}{ Sample } & $\begin{array}{c}\text { Corrosion current density } \\
\left(\mathbf{m A} / \mathbf{c m}^{2}\right)\end{array}$ \\
\hline Substrate & 0.036 \\
Coating 1 $(1250 \mathrm{~W})$ & 0.026 \\
Coating 2 $(1500 \mathrm{~W})$ & 0.023 \\
Coating 3 $(1750 \mathrm{~W})$ & 0.027 \\
\hline
\end{tabular}




\section{Accomplishments}

The project successfully accomplished all its objectives. It demonstrated the technical feasibility and the advantages of using high-energy-laser and IR plasma lamp methods for coating iron aluminide on a low alloy steel to improve its wear, oxidation resistance, and corrosion resistance properties.

\subsection{Technical Accomplishments}

- This research developed reliable, efficient, and economical methods based on high-energy-laser and IR plasma lamp methods for coating ceramic and intermetallic materials on ferrous materials. These methods were demonstrated primarily for intermetallic coatings on structural steel (AISI 4340), but their feasibility for coating ceramic systems such as $\mathrm{TiC}$ and $\mathrm{TiB}_{2}$ on ferrous (steels) and nonferrous (aluminum) metals was also proved.

- The coating microstructures were thoroughly studied to understand their improved response to chemical (corrosion, oxidation) and physical (hardness and wear) stresses as function of processing parameters.

- The coating equipment (lasers and IR plasma lamps) was configured to process the components in a variety of sizes and shapes and is ready for processing industrial components in a production environment.

- Process conditions and the composition of precursor coating must be carefully selected to retain iron aluminides on the coating surfaces.

- Under appropriate processing conditions, coatings free of porosity and cracks can be obtained using this technique.

- The hardness of the coatings and the heat-affected zones is a strong function of the processing parameters and hence can be tailor-made for the application. In the case of the samples processed with the IR plasma arc lamp, the hardness varies with the processing conditions. Processing conducted at a lower energy density $\left(2025 \mathrm{~W} / \mathrm{cm}^{2}\right)$ for the IR lamp produced a harder coating layer $(>1.5 \times$ harder $)$ than did higher energy density $\left(2350 \mathrm{~W} / \mathrm{cm}^{2}\right)$ processing. Similar trends for hardness were observed with the laser-based technique: The hardness values within the coating were much larger (Knoop hardness values $>400$ ) than those obtained for the base material (Knoop hardness values $<300)$. In addition, laser processing conducted at higher power $(1750 \mathrm{~W})$ produced coatings of lower hardness compared with the coatings produced at lower power $(1200 \mathrm{~W})$. Thus, with both the IR and the laser methods, processing at lower energies yielded coatings with higher wear resistance than did processing at higher energies. The evolution of intermetallic compounds (stoichiometry) in the coating was considered to be responsible for these changes. At higher-energy processing the stoichiometry of the coating was observed to be rich in aluminum, unlike that processed at lower energy, thereby providing inferior hardness and wear properties.

- The better corrosion resistance of laser-coated iron-aluminide than of the base steel may be due to the superior oxide layer offered by mixed oxides. The aluminide in the composite coating was responsible for reducing corrosion and oxidation. The variation in corrosion current and oxidation resistance clearly indicates the influence of laser parameters in improving resistance. The Fe-Al coated samples exhibited significantly lower corrosion current ( $\left.\mathrm{I}_{\text {corr }}\right)$ in both sulfuric acid and sodium chloride solutions. The corrosion current roughly translates to corrosion rate. In other words, the laser-coated samples are significantly more corrosion-resistant than the base materials.

- Experiments involving oxidation in air, done with TGA, indicated that laser-processed samples were more oxidation-resistant than the substrate. All the time-weight gain/area relationships were either 
cubic (the majority of instances) or parabolic. In other words, there is some intrinsic oxidation resistance in the coating as well as in the substrate.

\subsection{Technology Transfer}

The technical developments and laser-coating processes that grew out of this project were shared with various industrial organizations and universities. A proposal was submitted and later funded that was based in part on the results of this research. This later project focused on wear components (sieves, screens, and paddles) in the mining industry and involved seven mining companies, two component manufacturers, three industrial outreach organizations, and a university.

\subsection{Commercialization}

In light of these observations and project objectives, we achieved several project goals. We developed reliable, efficient, and economical methods based on high-energy-laser and IR-plasma-lamp processing for coating ceramic and intermetallic materials onto ferrous materials. The techniques developed were proved to be feasible mostly for intermetallic coatings on structural steel (AISI 4340), but their feasibility was also proved for coating ceramic systems such as $\mathrm{TiC}$ and $\mathrm{TiB}_{2}$ on ferrous (steel) and nonferrous (aluminum) metals. The coating microstructures were thoroughly studied to understand their improved response to chemical (corrosion, oxidation) and physical (hardness and wear) stresses as a function of processing parameters. The coating equipment (lasers and IR plasma lamps) was configured to process components of a variety of sizes and shapes and is ready for use in processing industrial components in a production environment.

The mining project noted in Sect. 1.2 is nearing completion. Industrial trials of laser-coated sieves and screens are showing a $3 \times$ improvement in wear performance in industrial trials.

\subsection{Publications}

The following publications were based on the results obtained during the project:

G. Muralidharan, P. G. Engleman, C. A. Blue, V. K. Sikka, A. K. Singh, A. Khangar, and N. B. Dahotre, "Laser-Assisted Surface Modification of 4340 Steel with Iron Aluminum Alloys," Proceedings of Materials Research Society (MRS) Symposium 750, 2003.

G. Muralidharan, C. A. Blue, V. K. Sikka, and N. B. Dahotre, "Surface Modification of 4340 Steel with Iron Aluminides using High-Energy-Density Processes," 2:357-66 in Engineered Steel Surfaces, Proceedings of MS\&T-04, New Orleans, September 2004. 


\section{Conclusions}

This project provided educational and hands-on training to three graduate students and one post-doctoral student from the University of Tennessee. These students are now working at high-technology companies: Milwaukee Tools, Chromalloy, and Intel. Two of these companies are involved in developing and supplying wear-resistant materials and components to industry.

This was a university-knowledge-based project. It provided an understanding of and showed the feasibility of laser processing of graded wear-resistant coatings for aluminide, boride, and carbide materials. In addition, it led to an industrial-scale project.

The performance of university-based projects in conjunction with a DOE national laboratory and that laboratory's unique R\&D capabilities provides improved opportunities for technology development and implementation. 



\section{Recommendations}

Based on the experience of the present project the following recommendations are made:

- Work should be initiated for development of $\mathrm{Fe}-\mathrm{Al} / \mathrm{TiB}_{2}$ coatings on 4340 steel.

- Further development of Fe-Al coating on 4340 steel should focus on optimization of process conditions and alloy composition.

- Following the above studies, dedicated efforts should be undertaken to coat selected industrial components for field tests. These efforts should focus on identifying one industrial sector and corresponding target components. 



\section{References}

1. Hongbo Guo, Xiaofang Bi, Shengkai Gong, and Huibin Xu, "Microstructure investigation on gradient porous thermal barrier coating prepared by EB-PVD," Scripta Materialia 44, no. 4, 683687 (2001).

2. U. Schulz, S. G. Terry, and C. G. Levi, "Microstructure and texture of EB-PVD TBCs grown under different rotation modes," Materials Science and Engineering A 360, nos. 1-2, 319-329 (2003).

3. Cheng-Shi Chen, Chuan-Pu Liu, C.-Y. A. Tsao, and Heng-Ghieh Yang, "Study of mechanical properties of PVD ZrN films, deposited under positive and negative substrate bias conditions," Scripta Materialia 51, no. 7, 715-719 (2004).

4. D. W. Stollberg, J. M. Hampikian, L. Riester, and W. B. Carter, "Nanoindentation measurements of combustion CVD Al2O3 and YSZ films," Materials Science and Engineering A 359, nos. 1-2, $112-118$ (2003).

5. J. G. Kim and Jin Yu, "Comparative study of residual stresses measurement methods on CVD diamond films," Scripta Materialia 39, no. 6, 807-814 (1998).

6. A. Paúl and J. A. Odriozola, "Development of a modified CVD coating process for the enhancement of the high-temperature oxidation resistance of $\mathrm{Cr}_{2} \mathrm{O}_{3}$ and $\mathrm{Al}_{2} \mathrm{O}_{3}$ forming alloys," Materials Science and Engineering A 300, nos. 1-2, 22-33 (2001).

7. H. E. Hintermann, "Advances and development in CVD technology," Materials Science and Engineering A 209, nos. 1-2, 366-371 (1996).

8. M. Uma Devi, "Microstructure of $\mathrm{Al}_{2} \mathrm{O}_{3}-\mathrm{SiC}$ nanocomposite ceramic coatings prepared by highvelocity oxy-fuel flame spray process," Scripta Materialia 50, no. 7, 1073-1078 (2004).

9. Zhenghao Gan and Heong Wah Ng, "Experiments and inelastic finite element analyses of plasmasprayed graded coatings under cyclic thermal shock," Materials Science and Engineering A 385, nos. 1-2, 314-324 (2004).

10. Z.-W. Li, W. Gao, D.-Y. Ying, and D.-L. Zhang, "Improved oxidation resistance of Ti with a thermal sprayed $\mathrm{Ti}_{3} \mathrm{Al}(\mathrm{O})-\mathrm{Al}_{2} \mathrm{O}_{3}$ composite coating," Scripta Materialia 48, no. 12, 1649-1653 (2003).

11. Erdal Celik and Ozkan Sarikaya, "The effect on residual stresses of porosity in plasma sprayed $\mathrm{MgO}-\mathrm{ZrO}_{2}$ coatings for an internal combustion diesel engine," Materials Science and Engineering A 379, 1-2, 11-16 (2004).

12. Y. Bhambri, V. K. Sikka, L. R. Walker, M. L. Santella, G. Muralidharan, and J. W. Hales, "Al enrichment of carbon steels through weld overlay process for improved oxidation resistance," Materials Science and Engineering A 394, 1-2, 249-255 (2005).

13. I-Hsuang Lo and Wen-Ta Tsai, "Effect of heat treatment on the precipitation and pitting corrosion behavior of 347 SS weld overlay," Materials Science and Engineering A 355, 1-2, 137-143 (2003).

14. Narendra B. Dahotre, C. Xiao, W. Boss, M. H. McCay, and T. D. McCay, "Coating ceramic composites by a laser in situ reaction technique," Journal of the Mineral, Metals, and Materials Society 7, no. 10, 51-53 (1995).

15. N. B. Dahotre, M. H. McCay, and T. D. McCay, "Laser Bonding Process for Ceramic Articles," U.S. Patent 5,503,703, April 2, 1996. 
16. T. D. McCay, M. H. McCay, and Narendra B. Dahotre, “Apparatus for Laser Alloying Induced Improvement of Surfaces,” U.S. Patent 5,961,861, October 5, 1999.

17. T. D. McCay, M. H. McCay, and Narendra B. Dahotre, "Method for Laser Induced Improvement of Surfaces," U.S. Patent 5,985,056, November 16, 1999.

18. Narendra B. Dahotre, C. Xiao, W. Boss, M. H. McCay, and T. D. McCay, "Laser induced reaction coating of ceramic on ceramic composite for enhanced high temperature corrosion resistance," Transactions of the Metal Finishers' Association of India 7, no. 1, 7-22 (1998).

19. Arvind Agarwal and Narendra B. Dahotre, "Pulse electrode deposition of superhard boride coatings on ferrous alloy," Surface Coatings and Technologies 106, nos. 2-3, 242-250 (1998).

20. Arvind Agarwal, Narendra B. Dahotre, and T. S. Sudarshan, "Evolution of interface in pulsed electrode deposited titanium diboride on copper and steel," Surface Engineering 1, no. 1, 27-32 (1999).

21. Kunal Ghosh, M. H. McCay, and Narendra B. Dahotre, "Formation of a wear-resistant surface on Al by laser aided in situ synthesis of $\mathrm{MoSi}_{2}$," Journal of Materials Processing Technology 88, 169179 (1999).

22. Arvind Agarwal, Narendra B. Dahotre, and L. F. Allard, "Ceramic/metal interface in laser deposited hard refractory composite coating: Electron microscopy study," Practical Metallography 36, no. 5, 250-263 (1999).

23. Arvind Agarwal and Narendra B. Dahotre, "Synthesis of boride coating on steel using high energy density processes: Comparative study of evolution of microstructure," Journal of Materials Characterization 42, no. 1, 31-44 (1999).

24. Arvind Agarwal and Narendra B. Dahotre, "Laser surface engineering of steel for hard refractory ceramic composite coating," International Journal of Refractory Materials and Hard Metals 17, 283-293 (1999).

25. Arvind Agarwal and Narendra B. Dahotre, "Pulsed electrode surfacing of steel with TiC coating: Microstructure and wear properties," Journal of Materials Engineering and Performance 8, no. 4, 479-486 (1999).

26. Arvind Agarwal and Narendra B. Dahotre, "Laser deposited titanium diboride coating for protection of molten aluminum handling tools and molds," Journal of Lasers in Engineering 9, 169-193 (1999).

27. Narendra B. Dahotre and Arvind Agarwal, "Refractory ceramic composite coating via laser surface engineering," Journal of Minerals, Metals, and Materials 51, no. 4, 19-21 (1999).

28. Arvind Agarwal and Narendra B. Dahotre, "Evaluation of laser surface engineered boride coating in various accelerated and oxidation environments," Corrosion Prevention and Control 46, no. 5, 111-121, 132 (1999).

29. Lalitha R. Katepelli, Arvind Agarwal, and Narendra B. Dahotre, "Laser surface engineered TiC coating on 6061 Al alloy: Microstructure and wear," Applied Surface Science 153, nos. 2-3, 65 (1999).

30. Lalitha R. Katipelli, Arvind Agarwal, and Narendra B. Dahotre, "Interfacial strength of laser surface engineered TiC coating on $6061 \mathrm{Al}$ using four-point bend test," Materials Science and Engineering, accepted for publication, April 15, 2000.

31. Arvind Agarwal and Narendra B. Dahotre, "Functionality of laser surface engineered composite titanium diboride coating," Journal of Minerals, Metals, and Materials 52, no. 1 (2000). 
32. Arvind Agarwal and Narendra B. Dahotre, "In situ synthesis of intermetallic and ceramic coatings using pulse electrode surfacing," Scripta Materialia 42, no. 5, 493-498 (2000).

33. Anuradha Godavarty, Arvind Agarwal, and Narendra B. Dahotre, "Neural networks in studies on oxidation behavior of laser surface engineered composite boride coating," Journal of Applied Surface Science, in press, February 7, 2000.

34. Arvind Agarwal and Narendra B. Dahotre, "Comparative wear in titanium diboride coatings on steel using high energy density processes," WEAR, accepted for publication, March 9, 2000.

35. Arvind Agarwal and Narendra B. Dahotre, "Laser engineered titanium boride coating," Advanced Materials \& Processes 156, no. 10, 43-45 (2000).

36. Arvind Agarwal and Narendra B. Dahotre, "Elevated temperature oxidation of laser engineered composite boride coating on steel," Metallurgical and Materials Transactions A 31A, 461-473 (2000).

37. Arvind Agarwal and Narendra B. Dahotre, "Mechanical properties of laser engineered composite boride coating on steel: A nanoindentation approach," Metallurgical and Materials Transactions A 31A, 401-407 (2000).

38. C. A. Blue, V. K. Sikka, R. A. Blue, and R. Y. Lin, "Infrared transient-liquid-phase joining of SC5-6 (beta) 21S titanium matrix composite," Metallurgical and Materials Transactions A 27A, 4011-4018 (1996).

39. C. A. Blue and V. K. Sikka, "Infrared transient-liquid-phase joining of gamma titanium," presented at TMS Annual Meeting, Anaheim, Calif., February 4-8, 1996.

40. Hidenobu Shiroishi and Tatsuhiro Okada, "Open-source electrochemical measurement system equipped with macro language for successive measurements," Journal of Computational Chemistry, Japan 3, no. 2, 71-76 (2004).

41. A. J. Bard and L. R. Faulkner, Electrochemical Methods: Fundamentals and Applications, 2nd ed., John Wiley and Sons, New York, 2001.

42. T. B. Massalski, Binary Alloy Phase Diagrams, ASM International, Materials Park, Ohio, 1986.

43. U. R. Kattner and B. P. Burton, Phase Diagrams of Binary Iron Alloys, ed. H. Okamoto, ASM International, Materials Park, Ohio, 1993, p. 12.

44. J. A. Hawk, and D. E. Alman, Materials Science and Engineering A-Structural Materials A239240, 899 (1997).

45. D. E. Alman, J. A. Hawk, J. H. Tylczak, C. P. Dogan, and R. D. Wilson, WEAR 251, 875 (2001).

46. D. E. Alman, J. H. Tylczak, J. A. Hawk, and J. H. Schneibel, Materials Science and Engineering A-Structural Materials A329, 602 (2002).

47. C. T. Liu, E. P. George, P. J. Maziasz, and J. H. Schneibel, Materials Science and Engineering AStructural Materials 258, 84 (1998).

48. P. F. Tortorelli, J. H. Devan, G. M. Goodwin, and M. Howell, Elevated Temperature Coatings: Science and Technology I, eds. N. B. Dahotre, J. M. Hampikian, and J. J. Stiglich, TMS, Warrendale, Penn., 1994, p. 204.

49. P. F. Tortorelli, I. G. Wright, G. M. Goodwin, and M. Howell, Elevated Temperature Coatings: Science and Technology II, eds. N. B. Dahotre and J. M. Hampikian, TMS, Warrendale, Penn., 1996, p. 175. 
50. P. F. Tortorelli, G. M. Goodwin, M. Howell, and J. H. Devan, Heat Resistant Materials II:

Proceedings of the 2nd International Conference on Heat-Resistant Materials, eds. K. Natesan, P. Ganesan, and G. Lai, ASM International, Materials Park, Ohio, 1995, p. 585.

51. S. W. Banovic, J. N. Dupont, P. F. Torterelli, and A. R. Marder, Welding Journal 78, 23-s (1999).

52. J. H. Schneibel, R. Subramanian, K. B. Alexander, and P. F. Becher, Proceedings of the International Symposium on Nickel and Iron Aluminides: Processing, Properties and Applications, ASM International, Materials Park, Ohio, 1995, p. 329.

53. E. Scheil, Zeitschrift für Metallkunde 34, 70-73 (1942).

54. M. Hillert and B. Sundman, CALPHAD 14, 111 (1990).

55. Y. Zhou, Xuesong Jin, Y. M. Mukovskii, and I. V. Shvets, "Kinetics of oxidation of low-index surfaces of magnetite," Journal of Physics: Condensed Matter 16, 1-12 (2004).

56. M. Ratto, E. Ricci, E. Arato, and P. Costa, "Oxidation of metals with highly reactive vapors: Extension of Wagner theory," Metallurgical and Materials Transactions B 32B, 903 (2001).

57. M. C. Garcia-Alonso, M. F. Lopez, M. L. Escudero, J. L. Gonazalez-Carrasco, and D. G. Morris, "Corrosion behavior of $\mathrm{Fe}_{3} \mathrm{Al}$ type intermetallic in a chloride containing solution," Intermetallic 7, 185-191 (1999).

58. M. L. Escudero, M. C. Garcia-Alonso, J. L. Gonazalez-Carrasco, M. A. Munoz-Morris, M. A. Montealegre, C. Garcia Oca, D. G. Morris, and S. C. Deevi, "Possibilities for improving the corrosion resistance of $\mathrm{Fe}-40 \mathrm{Al}$ intermetallic strip by prior oxide protection," Scripta Materialia $\mathbf{4 8}$, 1549-1554 (2003).

59. M. F. Lopez and M. L. Escudero, "Corrosion behavior of FeAl type intermetallic compounds," Electrochem Acta 43, 671-678 (1998).

60. R. A. Buchanan, J. G. Kim, R. E. Ricker, and L. A. Heldt, "Aqueous corrosion of intermetallic alloys," in Physical Metallurgy and Processing of Intermetallic Compounds, eds. N. S. Stolof and V. K. Sikka, Chapman and Hall, Norwell, Mass., 1994, p. 517.

61. T. C. Totemeier, R. N. Wright, and W. D. Swank, "Mechanical and physical properties of highvelocity oxy-fuel-sprayed iron aluminide coatings," Metallurgical and Materials Transactions A 34, 2223-2231 (2003).

62. R. Balasubramanium, "On the role of chromium in minimizing room temperature hydrogen embitterment in iron aluminides," Scripta Materialia 34, 127-133 (1996). 